\title{
ON THE RELATIONSHIP BETWEEN MOBILITY, POPULATION GROWTH, AND CAPITAL SPENDING IN THE UNITED STATES
}

\author{
Marco Bassetto \\ Leslie McGranahan \\ Working Paper 16970 \\ http://www.nber.org/papers/w16970
NATIONAL BUREAU OF ECONOMIC RESEARCH
1050 Massachusetts Avenue
Cambridge, MA 02138 \\ April 2011
}

We thank Gadi Barlevy and Mariacristina De Nardi for helpful suggestions and R. Andrew Butters and Hao Zou for valuable research assistance. Marco Bassetto gratefully acknowledges the National Science Foundation for support through grant 0754551. The views expressed herein are those of the authors and do not necessarily reflect the views of the National Bureau of Economic Research.

NBER working papers are circulated for discussion and comment purposes. They have not been peerreviewed or been subject to the review by the NBER Board of Directors that accompanies official NBER publications.

(C) 2011 by Marco Bassetto and Leslie McGranahan. All rights reserved. Short sections of text, not to exceed two paragraphs, may be quoted without explicit permission provided that full credit, including (C) notice, is given to the source. 
On the Relationship Between Mobility, Population Growth, and Capital Spending in the United States

Marco Bassetto and Leslie McGranahan

NBER Working Paper No. 16970

April 2011

JEL No. E62,H41,H71

\begin{abstract}
$\underline{\text { ABSTRACT }}$
In this paper, we investigate the relationship between public capital spending and population dynamics at the state level. Empirically, we document two robust facts. First, states with faster population growth do not spend more (per capita) to accommodate the needs of their growing population. Second, states whose population is more likely to leave do tend to spend more per capita than states with low gross emigration rates. To interpret these facts, we introduce an explicit, quantitative political-economy model of government spending determination, where mobility and population growth generate departures from Ricardian equivalence by shifting some of the costs and benefits of public projects to future residents. The magnitude of the empirical response of capital spending to mobility is at the upper end of what can be explained by the theory with a plausible calibration. In the model, more mobile voters favor more spending because the maturity of states' debt is very long term and costs are shifted into the future more than benefits.
\end{abstract}

\author{
Marco Bassetto \\ Research Department \\ Federal Reserve Bank of Chicago \\ 230 S. LaSalle Street \\ Chicago, IL 60604 \\ and NBER \\ mbassetto@frbchi.org \\ Leslie McGranahan \\ Federal Reserve Bank of Chicago \\ leslie.mcgranahan@chi.frb.org
}




\section{Introduction}

The sharp recession recently experienced by the United States has highlighted once more the plight of states whose finances are bound by constitutional restrictions on their indebtedness. The gap between many states' revenue projections and their anticipated expenses calls into serious question their ability to balance their books without substantial help from the federal government, which is not bound by similar rules. Throughout the recession, the federal government has been able to borrow large resources from the capital markets.

While almost all states are in principle prevented from borrowing to cover their ordinary budget, most of them are permitted to issue bonds to pay for capital improvements. This rule, commonly known as "the golden rule," has long been rationalized with the fact that capital improvements benefit generations to come, who should be called to share the burden. ${ }^{1}$ Current expenditures presumably benefit only the current generation who should therefore bear all the costs. Of course, such a rationale only holds in an economy that is far from Ricardian equivalence, for otherwise government debt would have no effects on allocations and welfare (Barro [4]).

In this paper, we look at the evidence that variation across states in capital spending is driven by departures from Ricardian equivalence stemming from mobility and population growth through the lens of a model that explicitly incorporates an interaction between dynamic economic and political decisions.

To this end, we build a dynamic political-economy model, where voters choose the provision of public goods anticipating that their future costs (and benefits) will be shared with incomers and will not be borne (and enjoyed) by a household once it emigrates. Our model builds on Bassetto with Sargent [7], generalizing results to an environment with many states and timevarying demographics, so that the parameters of the model can be directly matched to the regression coefficients from our state-level empirical analysis. More generally, our research fits into a broader research agenda that studies the interaction of dynamic economic and political decisions to understand fiscal policy and government debt; a few examples of this pursuit are Klein, Krusell and Ríos-Rull [17], Azzimonti [1], Battaglini and Coate [8, 9, 10], Azzimonti,

\footnotetext{
${ }^{1}$ See e.g. Studensky [25].
} 
Battaglini and Coate [2], Song, Storesletten, and Zilibotti [24], and Bachmann and Bai [3].

Our starting point is a simple environment where the population is spread across different states, and voters choose public spending year by year, taking into account the exogenous prospects for mobility that they face and an exogenous path for population growth in the state they reside in. ${ }^{2}$ Voters discount future costs and benefits of their policy choices more heavily than efficiency would dictate: this occurs because they neglect costs and benefits that will accrue to future residents of the state that are not yet present. This effect will be larger, the faster a state's population is growing or the more turnover among residents. In the absence of any restriction on government indebtedness we would thus expect states to run large deficits. However, as mentioned above, the manifestation of the golden rule in the U.S. states prevents voters from financing non-capital expenses with debt. If strictly enforced, the golden rule fully restores incentives to provide the correct amount of nondurable public goods: this is because both costs and benefits accrue immediately, and no long-term consequences emerge. However, in the case of public capital, both benefits (of current investment) and costs (of current debt issuance) spill over into the future. These costs and benefits could align if debt issuance were structured so that the debt was paid off at the same time as the benefits accrued, but in practice the two need not be aligned correctly. In particular, whether costs or benefits will be shifted further into the future depends on many parameters, but especially on the duration of capital and the limits on the maturity of debt and the fraction of debt financing. The shorter the duration of capital, the longer the maturity of debt, and the larger the fraction of debt financing, the more costs are shifted to the future relative to benefits, to the point that voters might actually be induced to overspend.

The degree by which cost/benefit mismatches lead to inefficient spending depends on how far away the demographic structure is from Ricardian equivalence. At one extreme, in a world of no mobility and no population growth, the set of voters would be fixed and the distribution

\footnotetext{
${ }^{2} \mathrm{By}$ assuming that the evolution of population is exogenous, we abstract from the capitalization effects that play a very important role in the literature on urban economics. A recent survey of this research is in Ross and Yinger [21]. By looking at state-level data rather than local data, we expect capitalization to be much less prevalent.
} 
of costs and benefits over time should be irrelevant. In the presence of mobility and population growth, the model delivers quantitative predictions on how these population attributes affect capital spending. It is these predictions that we take to the data.

In our empirical exercise we use state-level panel data to document two main facts:

1. For a given population growth rate, capital spending is positively related to mobility, i.e., it declines with the fraction of the population that remains in the state in any given year. This implies that the capital stock increases with gross migration.

2. Capital spending by the states reacts to population growth less than would be needed to preserve a constant capital stock per capita. This implies that the capital stock per capita declines with population growth.

While mobility has sometimes appeared in previous empirical studies of state-level spending (see Poterba [19]), to our knowledge we provide the first systematic evidence that gross interstate mobility is an important predictor of state-level spending, both using within- and across-state variation. The predictive power of gross state mobility persists even after we control for other measures of mobility, such as net interstate mobility or mobility within the state. This is encouraging for our model, where gross state mobility, as distinct from those alternative measures, plays a central role.

Our main objective is to interpret the magnitudes of the coefficients that we find relative to our model's sharp quantitative predictions about the degree of departure from Ricardian equivalence. A positive relationship between mobility and capital spending is interpreted by the model as evidence of too much borrowing: when future costs exceed the benefits, a more mobile population is more prone to overspending. The magnitude of the empirically measured link between mobility and spending is economically important, and it is in fact at the upper end of what the theoretical model can deliver.

In matching the second fact to the theory, accounting properly for implementation delays is important. In a world in which public projects are completed within a period (a year) of their approval, it would take implausibly large departures from Ricardian equivalence for public investment to fall as much behind population growth as it does in our data. But in reality, 
gathering bids, signing contracts, and completing construction take more than a year. In the presence of implementation delays, the model predicts a weaker link between capital spending and population growth: in the short run, spending is predetermined and investment per capita may respond negatively to population growth; in the longer run, a growth shock today will not fully persist into the future, and implementation delays will then dampen the optimal response by the voters. We are able to derive testable implications that are independent of the precise structure of implementation lags: these are based on measuring the response of spending to distributed lags of population growth (and mobility). These measures suggest that the relationships in the data are not far from what the model would predict if states are adhering to the golden rule.

Our final experiment estimates the fraction of debt financing that would be needed in the model to match the response of public investment to mobility and population growth in the data. Although our overidentifying restrictions are often statistically rejected, the estimate for public investment is close to $100 \%$, the value that should arise if states abide by the golden rule. Similar inference for current expenses suggests a small, but positive fraction of debt financing; this is what we would expect if there is a little margin to bend the golden rule.

In the remainder of the paper, section 2 presents the model through which we interpret the data; it derives the equilibrium relationship between government spending, population growth, and mobility, provides intuition on its nature, and discusses ways in which this relationship can be informative about the parameters of the model. Section 3 describes the data and provides a brief institutional overview. Our main results are presented in section 4, while section 5 speculates on directions for future research.

\section{Model}

\subsection{Primitives}

The model we adopt is based on Bassetto with Sargent [7]. However, we explicitly introduce here the sources of variation across states (jurisdictions) and over time that will form the basis of our estimation procedure. While highly stylized, the model we present provides an explicit 
account of the forces that drive political decisions, and thus offers a transparent interpretation of the findings of our empirical exercise.

We consider $N$ states (jurisdictions), each populated by a continuum of households. Each state $n$ is characterized by the following random variables:

- $n_{s t}$, the population growth in state $s$ at time $t$.

- $\theta_{s t}$, the probability that a household living in state $s$ at $t-1$ is in the same state at $t$. For simplicity, we assume that the probability of moving is independent of age; time variation in mobility will thus affect all residents uniformly. ${ }^{3}$

- $\phi_{s t}$, a measure of the household preference for public goods in the state;

We assume that all residents of a state share the same mobility and the same preferences for (state-level) public goods. ${ }^{4}$ By assuming that these random variables depend on the state, rather than the household, we make our analysis tractable, but our results would be robust to the extent that moving costs are high. ${ }^{5}$

Within period $t$, a household residing in state $s$ has preferences given by

$$
c_{i t}+\phi_{s t} \frac{G_{s t}^{1-\sigma}}{1-\sigma}
$$

where $c_{i t}$ is consumption of a private good by household $i$ (residing in state $s$ ) and $G_{s t}$ is the per capita level of a state-level public good. ${ }^{6}$

\footnotetext{
${ }^{3}$ As shown in Bassetto and Lepetyuk [6] (e.g., figure 1), variation by age is not as important, except for the old that are far from being pivotal. For the same reason, we can safely abstract from the probability of death: except for the old, this is much smaller than the probability of moving. Introducing a constant probability of death would complicate our intermediate steps, but would not affect the final expressions that we take to the data.

${ }^{4}$ Upon moving, each household thus inherits a new mobility and preference parameter, based on its new state of residence.

${ }^{5}$ For evidence of limited mobility across states, see Meyer[18] and Gelbach [13]. Kennan and Walker [16] also estimate very high moving costs for the large majority of residents of a state, limiting the pool of potential movers. A model of policy determination with endogenous mobility is developed in Bassetto [5].

${ }^{6}$ We assume that public goods are subject to congestion externalities. This seems appropriate for state-level
} 
Households discount the future at a rate $\beta$. We assume that the probability that a household that moves from one state to another will move back is negligible. Because of this, households discount future benefits from the public goods and future taxes in the state in which they reside by $\beta \theta_{s t+1}$.

In each period, each person alive produces $y$ units of output, which can be either consumed as a private $\operatorname{good}^{7}$ or invested in the public good. The per capita level of the public good evolves in the following manner:

$$
G_{s t}=\frac{1-\delta}{1+n_{s t}} G_{s t-1}+\gamma_{s t},
$$

where $\delta$ is the depreciation rate of the public good and $\gamma_{s t}$ is public spending per capita in period $t$ in state $s$. In our empirical specifications, we will consider several public goods, characterized by different degrees of durability; in particular, we will constrast current expenditures (for which we assume $\delta=1$ ) to capital expenditures. The analysis developed here immediately generalizes to multiple public goods by assuming that each good enters additively in the utility function. ${ }^{8}$ In particular, our key equations (7) and (9) will hold for each good independently.

Each state has a government that is empowered to levy income taxes and produce public goods. 9

The government faces a budget constraint, that links the evolution of its debt per capita $B_{s t}$ to the deficit it runs in every period:

$$
B_{s t}=\left(1+r_{t}\right) \frac{B_{s t-1}}{1+n_{s t}}+\gamma_{s t}-T_{s t}
$$

where $r_{t}$ is the real interest rate, and $T_{s t}$ are tax revenues per capita.

public goods, since it is doubtful that the relative magnitude of Delaware vs. California is a major driver of public amenities in the two states. Supporting this view, our population-based measure of state size is not significant in our regressions.

${ }^{7}$ The private good is nondurable. Private capital could be introduced with no effect on the results, if income taxes are restricted to labor; see Bassetto with Sargent [7].

${ }^{8}$ The preferences over $M$ public goods would thus be described by $c_{i t}+\sum_{j=1}^{M} \phi_{s j t} \frac{G_{s j t}^{1-\sigma_{j}}}{1-\sigma_{j}}$.

${ }^{9}$ Given that all residents of a state are identical and that location and income are exogenous, income taxes are equivalent to fixed lump-sum payments. 
Taxes and spending are chosen by majority vote each period by the residents of the state, ${ }^{10}$ subject to two borrowing restrictions. The first restriction limits to a value $x$ the fraction of public spending that can be financed with debt. The constitutions of most U.S. states prevent borrowing, except to finance capital expenditures; this would correspond to $x=0$ for current (nondurable) expenses, and $x=1$ for capital projects. ${ }^{11}$ We will both study the implications of setting $x$ to these values and make inference on $x$ from the data. The second restriction limits the duration of debt. In the model, this is represented by a parameter $\alpha$, which represents the minimal fraction of outstanding debt that must be retired in any given period. This parameter is a parsimonious representation of the limited duration of debt issued by U.S. states; for some states, this limit is imposed by their constitution, while in other cases it might be driven by other forces that are outside of the model, such as the lack of liquidity of maturities longer than 30 years. The two borrowing restrictions give rise to the following lower bound on taxes, given by the fraction of spending that cannot be financed with debt, plus the minimum debt repayment:

$$
T_{s t} \geq(1-x) \gamma_{s t}+\frac{\alpha+r_{t}}{1+n_{s t}} B_{s t-1}
$$

Given household preferences, the equilibrium interest rate of the economy is the constant $r_{t}=$ $(1-\beta) / \beta$.

\subsection{Equilibrium}

Details of the definition and characterization of an equilibrium are provided in the appendix. In brief, voters equate the marginal benefit of an additional unit of investment with its cost, taking into account the discounted value of future benefit and cost changes that are triggered by today's vote. We focus on Markov equilibria, where the equilibrium level of public capital is independent of the past. In these equilibria, any additional investment in public goods beyond the equilibrium

\footnotetext{
${ }^{10}$ Given our assumptions, all residents will share the same preferences, and the vote will be unanimous.

${ }^{11}$ Pension obligations are an important grey area in the states' and localities' budgets, as witnessed by the recent experience of states that have borrowed to fund these obligations. Funding pensions with debt violates the golden rule by transferring the costs of current employees to future taxpayers. Inman [14] shows evidence of strategic manipulation along these lines.
} 
level would only last for one period, and will be reversed in the subsequent period. This implies that the marginal benefit of a new project is equal to its marginal benefit in one period, which is $\phi_{s t} G_{s t}^{-\sigma}$. While the level of the public good is altered for only one period, the tax implications stretch into the future. On the cost side, equations (3) and (4) imply that an additional unit of $G_{s t}$ increases time- $t$ taxes in state $s$ by $1-x$ units. ${ }^{12}$ In period $t+1$, in accordance with the equilibrium, spending in the public good is reduced by $(1-\delta) /\left(1+n_{s t+1}\right)$ units to restore capital to the level that would have prevailed without the additional spending in period $t$. Period- $t+1$ taxes respond to this investment reduction by $(1-x)(1-\delta) /\left(1+n_{s t+1}\right)$. Period- $t+1$ taxes are also affected by the additional debt $(x)$ issued in period $t$. Of this debt, the state must pay interest (at a rate $(1-\beta) / \beta$ ) and a fraction $\alpha$ of principal. The combined effect for period $t+1$ is thus given by

$$
-\frac{(1-x)(1-\delta)}{1+n_{s t+1}}+\frac{x}{1+n_{s t+1}}\left(\frac{1-\beta}{\beta}+\alpha\right) .
$$

An additional unit of spending in period $t$ has no further effects on public spending beyond period $t+1$, but the consequences of debt from the changes in spending in both periods $t$ and $t+1$ linger, and taxes in period $t+j$ vary by the following amount:

$$
x \prod_{v=1}^{j} \frac{1}{1+n_{s t+v}}\left[\frac{1-\beta}{\beta}+\alpha\right][\delta-\alpha](1-\alpha)^{j-2}, \quad j>1 .
$$

Whether taxes increase or decrease after period $t+1$ depends on whether the public good depreciates faster or slower than the rate at which government debt is paid back. When the public good is not very durable and debt is paid back slowly, we have $\delta>\alpha$ and taxes increase in the long run.

To a resident of the state at time $t$, the expected present value of taxes per unit of public investment, $Q_{s t}$, is the discounted sum of all these present and future tax changes:

$$
\begin{aligned}
Q_{s t} \equiv & E_{t}\left\{1-x+\frac{\beta \theta_{s t+1}}{1+n_{s t+1}}\left[x\left(\frac{1-\beta}{\beta}+\alpha\right)-(1-x)(1-\delta)\right]+\right. \\
& \left.x\left[\frac{1-\beta}{\beta}+\alpha\right](\delta-\alpha) \sum_{j=2}^{\infty} \beta^{j}(1-\alpha)^{j-2} \prod_{v=1}^{j} \frac{\theta_{s t+v}}{1+n_{s t+v}}\right\},
\end{aligned}
$$

\footnotetext{
${ }^{12}$ It is straightforward to show that voters will always choose to postpone taxes as much as possible, i.e., they will choose taxes so as to make (4) bind.
} 
where $E_{t}$ is the conditional expectation taken with respect to the statewide shocks.

In voting, a resident will equate the marginal utility of the additional public good provision in period $t$ with the expected present value of tax changes that will be triggered by this additional provision:

$$
\phi_{s t} G_{s t}^{-\sigma}=Q_{s t} \Longrightarrow \log G_{s t}=\frac{1}{\sigma}\left(\log \phi_{s t}-\log Q_{s t}\right)
$$

This expression confirms that voters choose a level of public capital that is independent of past choices (if they expect future voters to do the same), thereby validating the nature of the equilibrium that we conjectured.

\subsection{Equilibrium Approximation: Capital}

To simplify our expressions, we linearize $\log Q_{s t}$ around $n_{s t}=0$ and $\theta_{s t}=1$, and assume that population growth and (one minus) the mobility rate follow $\mathrm{AR}(1)$ processes with autocorrelations $\rho_{n}$ and $\rho_{\theta}$ and long-term means $\bar{n}$ and $\bar{\theta}$. This yields the following expression for the present value of taxes per unit of investment that the current voters are expecting to pay:

$$
\begin{aligned}
\log Q_{s t} & \approx \log (1-\beta(1-\delta))+\frac{1+\bar{n}-\bar{\theta}}{1-\beta(1-\delta)}\left[\beta(1-\delta)-x \frac{1-\beta(1-\delta)}{1-\beta(1-\alpha)}\right]+ \\
& \frac{\rho_{n}\left(n_{s t}-\bar{n}\right)}{1-\beta(1-\delta)}\left[\beta(1-\delta)-x \frac{1-\beta \rho_{n}(1-\delta)}{1-\beta \rho_{n}(1-\alpha)}\right]-\frac{\rho_{\theta}\left(\theta_{s t}-\bar{\theta}\right)}{1-\beta(1-\delta)}\left[\beta(1-\delta)-x \frac{1-\beta \rho_{\theta}(1-\delta)}{1-\beta \rho_{\theta}(1-\alpha)}\right]
\end{aligned}
$$

To derive intuition, we consider three components of equation (7) in turn:

1. $\log (1-\beta(1-\delta))$. This is the only term that would apply if $n_{s t} \equiv \bar{n}=0$ and $\theta_{s t} \equiv \bar{\theta}=1$. With no population growth and no mobility ever, this is a standard representative-agent economy where Ricardian equivalence holds. Consequently, neither the fraction of debt financing $x$ not debt maturity $\alpha$ have any effect on public good provision. Furthermore, it is straightforward to verify that the representative agent votes for the efficient level of $G_{\text {st. }}{ }^{13}$

\footnotetext{
${ }^{13}$ See the appendix for the derivation of the efficient level.
} 
2. A term that captures the deviations from efficiency that arise when $\rho_{n}$ and $\rho_{\theta}$ are zero:

$$
\frac{1+\bar{n}-\bar{\theta}}{1-\beta(1-\delta)}\left[\beta(1-\delta)-x \frac{1-\beta(1-\delta)}{1-\beta(1-\alpha)}\right] .
$$

In this case, the expectations about future mobility and growth are equal to their unconditional values $\bar{n}$ and $\bar{\theta}$. When $x=0$ (there is no debt issuance), higher mobility $(1-\theta)$ and/or population growth $(n)$ between period $t$ and period $t+1$ imply a higher effective discount factor by the voters. As a result, costs to current voters go up, and this leads to an accordingly lower level of government investment (provided depreciation is less than full, i.e., $\delta<1)$. When debt issuance is allowed at the margin $(x>0)$, costs in the form of debt repayment are also shifted into the future, reducing the inefficiency caused by mobility and population growth. The degree to which borrowing is effective at restoring efficiency depends on the relationship between $\delta$ and $\alpha$ : $\delta$ measures the decay of capital (and hence the rate at which benefits shrink) into the future, whereas $\alpha$ measures the speed of debt repayment (and hence the rate at which costs shrink). The higher $\delta$ (the lower $\alpha$ ), the less debt is needed to restore efficiency. When $x$ goes above $\frac{\beta(1-\delta)(1-\beta(1-\alpha))}{1-\beta(1-\delta)}$, the term in brackets is negative, and costs are shifted further into the future than benefits, and deviations from Ricardian equivalence imply overspending.

This logic is also helpful in understanding the case in which $\rho_{\theta} \approx \rho_{n} \approx 1$. In this case, deviations from efficiency (derived from both this term and the remaining terms in equation (7)) are given by

$$
\frac{1+n_{s t}-\theta_{s t}}{1-\beta(1-\delta)}\left[\beta(1-\delta)-x \frac{1-\beta(1-\delta)}{1-\beta(1-\alpha)}\right],
$$

which is equal to the term (8) simply replacing the unconditional means $\bar{n}$ and $\bar{\theta}$ with the current values of the shocks $n_{s t}$ and $\theta_{s t}$, which are perceived as permanent shocks for the future.

3. The remaining terms in equation (7) capture the way in which the speed of the repayment schedule interacts with the demographic processes as $n_{s t}$ and $\theta_{s t}$ converge (in expectation) back to their long-run steady states. When $\rho_{n}$ and $\rho_{\theta}$ are less than 1 , the interaction between these terms and the one in equation (8) is less straightforward and the level of 
debt that restores efficiency will result from canceling out of the three terms where $x$ appears. In practice, our estimates of $\rho_{n}$ and $\rho_{\theta}$ are both close to one, so that the three levels of debt that cancel out each of the bracketed terms in equation (7) will be very similar, and the average will be close to $\frac{\beta(1-\delta)(1-\beta(1-\alpha))}{1-\beta(1-\delta)}$.

Based on the intuition developed above, the model predicts that the stock of public capital will be lower in states with more population growth and/or higher mobility if no borrowing is allowed. When enough borrowing of sufficiently long maturity is allowed, this relation reverses, and more population growth (mobility) is associated with higher capital. This is more likely to happen for capital that depreciates faster.

To gain further insight, in figures 1 and 2 we plot the log of the stock of the public good as a function of the fraction of households that stay within the state from one year to the next ("the stayers") and the degree to which debt financing is allowed. ${ }^{14}$ In both figures we set $\beta=0.96$, $\sigma=0.2$, and $\alpha$ so that the half-life of debt is 15 years; we set population growth to 0 (to isolate the effects of mobility), we assume constant mobility, and no implementation lags. Finally, we also assume constant preferences, and we normalize $\phi_{s t}$ so that the efficient provision of the public good (in logs) is 0 .

In figure 1 we set $\delta=0.03$, which may be appropriate for major infrastructure investment, whereas figure 2 adopts $\delta=0.06$, in line with many estimates of the depreciation of private capital.

Not surprisingly, figures 1 and 2 show that Ricardian equivalence holds if there is no mobility $(\theta=1)$, while spending departs more and more from the efficient level when the fraction of stayers decreases. More interestingly, the sign of this departure depends on the circumstances. Under a pure balanced budget $(x=0)$, we unambiguously obtain that public capital is underprovided. However, under $100 \%$ debt financing, when capital is not very durable $(\delta=0.06)$ costs are shifted into the future (relative to benefits) to an extent that makes it worthwhile for voters to actually overprovide public capital. In this case, increasing mobility (decreasing the fraction of stayers) increases the provision of public capital. The main implication observed in these figures is that,

\footnotetext{
${ }^{14}$ The effects of population growth are analogous to those of mobility, so we do not plot them here.
} 
for high degrees of debt financing, we should observe a positive relationship between the level of public capital and mobility for capital goods subject to rapid depreciation, and a negative relationship for very long-term projects.

\subsection{Equilibrium Approximation: Identification of Factors Affecting Investment}

The discussion above refers to the stock of public capital and assumes that projects are implemented as soon as they are approved. In the data, we actually observe the flows of public investment (and expenses in nondurable goods); moreover implementation lags are likely as bidding and contracting may wait until after voter or legislature approval and projects may take several years to complete. We adjust for both of these before we take our model to the data. In the model, the investment flow is captured by the variable $\gamma_{s t}$, which can be easily computed from (2) and (6). We account for implementation delays by assuming that capital projects are approved by voters $k$ years before they are implemented. Voters take into account the resulting shift of both costs and benefits into the future. ${ }^{15}$

\footnotetext{
${ }^{15}$ In our analysis, both benefits and costs are subject to the same delay. We are mostly concerned with delays arising from planning and bidding, periods in which little actual spending occurs.
} 
We generate the following expression for investment: ${ }^{16}$

$$
\begin{aligned}
& \log \gamma_{s t} \approx \log \delta+\frac{1}{\delta \sigma}\left\{E_{t-k} \log \phi_{s t}-(1-\delta) E_{t-k-1} \log \phi_{s t-1}-\delta \log (1-\beta(1-\delta))-\right. \\
& \frac{\beta \delta(1-\delta)}{1-\beta(1-\delta)}\left(1+\bar{n}-\bar{\theta}-\rho_{\theta}^{k+1}\left(\theta_{s t-k}-\bar{\theta}\right)+\rho_{n}^{k+1}\left(n_{s t-k}-\bar{n}\right)\right)+ \\
& x \delta\left[\frac{1+\bar{n}-\bar{\theta}}{1-\beta(1-\alpha)}+\frac{\rho_{n}^{k+1}\left(n_{s t-k}-\bar{n}\right)\left(1-\beta \rho_{n}(1-\delta)\right)}{(1-\beta(1-\delta))\left(1-\beta \rho_{n}(1-\alpha)\right)}-\frac{\rho_{\theta}^{k+1}\left(\theta_{s t-k}-\bar{\theta}\right)\left(1-\beta \rho_{\theta}(1-\delta)\right)}{(1-\beta(1-\delta))\left(1-\beta \rho_{\theta}(1-\alpha)\right)}\right]- \\
& \frac{\beta(1-\delta)^{2}}{1-\beta(1-\delta)}\left(\rho_{n}^{k+1}\left(n_{s t-k}-n_{s t-k-1}\right)-\rho_{\theta}^{k+1}\left(\theta_{s t-k}-\theta_{s t-k-1}\right)\right)+ \\
& \left.x(1-\delta)\left[\frac{\rho_{n}^{k+1}\left(n_{s t-k}-n_{s t-k-1}\right)\left(1-\beta \rho_{n}(1-\delta)\right)}{(1-\beta(1-\delta))\left(1-\beta \rho_{n}(1-\alpha)\right)}-\frac{\rho_{\theta}^{k+1}\left(\theta_{s t-k}-\theta_{s t-k-1}\right)\left(1-\beta \rho_{\theta}(1-\delta)\right)}{(1-\beta(1-\delta))\left(1-\beta \rho_{\theta}(1-\alpha)\right)}\right]\right\}+ \\
& \frac{1-\delta}{\delta}\left[n_{s t-k}+\frac{\rho_{n}\left(1-\rho_{n}^{k}\right)}{1-\rho_{n}}\left(n_{s t-k}-n_{s t-k-1}\right)\right]+k \bar{n}+\frac{\rho_{n}\left(1-\rho_{n}^{k}\right)}{1-\rho_{n}}\left(n_{s t-k}-\bar{n}\right)-\sum_{j=1}^{k} n_{s t-k+j}
\end{aligned}
$$

This equation shows how the parameters of the model affect the relationship between public investment, population growth, and mobility. Our empirical strategy is based on testing the model by running the corresponding regression:

$$
\log \gamma_{s t}=a+\sum_{j=0}^{J} b_{n j} n_{s, t-j}+\sum_{j=0}^{J} b_{\theta j} \theta_{s, t-j}+\epsilon_{s t}
$$

Interpreting the individual coefficients in the sums in (10) is difficult because the corresponding coefficients in (9) are very sensitive to implementation lags. As an example, using our baseline parameters of Table 1 , we would expect $b_{0} \approx 17$ if there are no implementation lags, while $b_{0}=-1$ with implementation lags of a year or longer. The intuition is straightforward: in the first case, investment ramps up immediately with population growth, to accommodate the needs of the additional population; in the second case, total investment is predetermined by the voters' previous decisions, so it actually falls in per capita terms if population grows faster, only to increase at a later date.

Fortunately, the dependence of individual coefficients on implementation lags can be overcome by aggregating distributed lags. These sums correspond to dynamic patterns of change in

\footnotetext{
${ }^{16}$ See the appendix for its derivation.
} 
population growth and mobility whose implications for investment can be established regardless of implementation lags:

$$
\begin{gathered}
B_{n}:=\sum_{j=0}^{J} \rho_{n}^{-j} b_{n j} \approx \frac{1-\delta}{\delta}+\frac{1-\delta-\rho_{n}}{\delta \sigma(1-\beta(1-\delta))}\left[\beta(1-\delta)-x \frac{1-\beta \rho_{n}(1-\delta)}{1-\beta \rho_{n}(1-\alpha)}\right], \\
B_{\theta}:=\sum_{j=0}^{J} \rho_{\theta}^{-j} b_{\theta j} \approx-\frac{1-\delta-\rho_{\theta}}{\delta \sigma(1-\beta(1-\delta))}\left[\beta(1-\delta)-x \frac{1-\beta \rho_{\theta}(1-\delta)}{1-\beta \rho_{\theta}(1-\alpha)}\right],
\end{gathered}
$$

and

$$
B_{\theta}^{*}:=\sum_{j=0}^{J} \frac{\partial \log \gamma_{s t}}{b_{\theta j}} \approx \frac{\rho_{\theta}^{k+1}}{\sigma(1-\beta(1-\delta))}\left[\beta(1-\delta)-x \frac{1-\beta \rho_{\theta}(1-\delta)}{1-\beta \rho_{\theta}(1-\alpha)}\right],
$$

where $J>k$ is any number greater than the number of years of delay in implementation.

$B_{n}$ corresponds to the change in investment in response to a shock in the growth rate of population of magnitude $\rho_{n}^{-J}$ in period $t-J$ that decays at the rate $\rho_{n}$ through period $t$ (attaining a magnitude of 1 in period $t$ ). $B_{\theta}$ has the same interpretation for a mobility shock. $B_{\theta}^{*}$ corresponds to the change in investment when the fraction of stayers increases by the same amount in periods $t-J$ through $t$.

Equations (11) and (12) are appealing in that they do not depend at all on the specific value $k$. However, inference based on these coefficients relies heavily on the interaction between the persistence of mobility and population growth and the depreciation of capital. The simple sum in (13) is much easier to interpret, and will not be very sensitive to $k$ when $\rho_{\theta}$ is close to one, as we estimate in the data. ${ }^{17}$

To gain further intuition, consider first what happens under efficient provision of the public good. The efficient level is given by

$$
\phi_{s t} G_{s t}^{-\sigma}=1-\beta(1-\delta) .
$$

\footnotetext{
${ }^{17}$ It might be surprising that the two sums given by (12) and (13), which are quite similar for $\rho_{\theta} \approx 1$, might have significantly different interpretations from the perspective of the model. The explanation for this apparent puzzle can be seen from equation (9). For the typical values of the depreciation rate and the discount factor, these expressions imply a very large coefficient in the difference between $\theta_{s t-k}$ and $\theta_{s t-k-1}$. Hence, even small changes in $\rho_{\theta}$ may have a significant impact on the overall sum. In the data, the high degree of autocorrelation in $\theta_{s t}$ implies that measuring the effect of the difference in mobility rates from one period to the next is difficult.
} The straight sum in (13) bypasses this difficulty. 
From equation (2), this implies that investment is

$$
\gamma_{s t}=\left(\frac{\phi_{s t}}{1-\beta(1-\delta)}\right)^{1 / \sigma}-\frac{1-\delta}{1+n_{s t}}\left(\frac{\phi_{s t-1}}{1-\beta(1-\delta)}\right)^{1 / \sigma}
$$

The efficient level of investment is driven by the total population of the state, independently of the gross migration flows. For this reason, $\theta_{s t}$ plays no role in equation (14), and our estimates of $B_{\theta}$ and $B_{\theta}^{*}$ would thus be zero. When a state's population is growing, equation (14) shows that additional investment is needed to provide a constant capital stock per capita. After taking logs and the appropriate linearization, the resulting coefficient $B_{n}$ would be equal to $(1-\delta) / \delta$, which is the first term in (11).

When $B_{\theta}$ and $B_{\theta}^{*}$ are different from zero, we can infer from their sign whether mobility is a force that generates underprovision or overprovision of public capital in the model. Take $B_{\theta}^{*}$ first, since it is the easier term to interpret. When no borrowing is allowed $(x=0)$, underprovision of public capital occurs, and this is more severe the lower $\theta_{s t}$ is, since a lower probability of staying magnifies departures from Ricardian equivalence. As can be seen from (13), this is reflected in $B_{\theta}^{*}>0$. As $x$ increases, $B_{\theta}^{*}$ decreases, until it eventually becomes negative when mobility starts being a factor that generates overprovision of public capital.

The coefficient $B_{\theta}$ embeds a level effect, that is identical to the one described for $B_{\theta}^{*}$, and a time-trend effect. The trend effect works in the opposite direction of the level effect. Consider the case of underprovision (say, $x=0$ ). $B_{\theta}$ measures the response to a shock that increased $\theta_{s t-1}$ by $\rho_{\theta}^{-1}$, and decayed to an increase by 1 in $\theta_{s t}$. This shock implies an increase in the desired level of capital that is greatest in period $t-1$. As of period $t$, the desired level of capital is still higher than without the shock, but the decay implies that it is lower than period $t-1$. Investment reflects this desire for drawing down the stock. When depreciation is low, undepreciated capital from the previous period is sufficiently high that drawing down the stock requires curtailing investment in period $t$, and the overall effect of the shock on investment can be negative in that period (even though $\theta_{s t}$ is higher than it would have been in the absence of the shock). In contrast, when depreciation is high, not much of the additional capital from period $t-1$ remains, and investment needs to remain elevated to deliver the higher period- $t$ capital stock that is warranted in consequence of the lingering positive shock to the fraction of 
stayers. We thus conclude that, for goods that are not too durable, underprovision is associated with $B_{\theta}>0$, whereas the reverse is true when $\delta<1-\rho_{\theta}$.

The intuition for $B_{n}$ is completely analogous to the one about $B_{\theta}$, except that the "neutral" value of this coefficient is $(1-\delta) / \delta$, due to the need to provide additional capital when the population grows faster. To discuss one of the cases, when $x=0$ more population growth leads to more underprovision of the public good. If $\delta>1-\rho_{n}$, this level effect dominates, and the response to population growth is smaller than $(1-\delta) / \delta$, the level that is necessary to preserve the stock of capital per capita. If $\delta<1-\rho_{n}$, then the trend effect dominates the level effect, and underprovision is associated with $B_{n}>(1-\delta) / \delta$.

We illustrate the working of the coefficients further by looking at their values under our baseline calibration, presented in Table 1, and exploring their sensitivity to various parameters.

At the parameter values of Table 1 we obtain the following values:

$$
B_{n} \approx 6.8, B_{\theta} \approx-3.5, B_{\theta}^{*} \approx-9.5
$$

Consider $B_{\theta}^{*}$ first. Our calibration implies that the benefits of capital goods are more weighted towards the present than the taxes needed to pay off the debt. This implies that $100 \%$ debt financing generates incentives for overprovision of capital (i.e., the term in brackets in (13) is negative). ${ }^{18}$ This incentive is lower, the closer we are to Ricardian equivalence and thus the higher the fraction of the population that stays within the state from one year to the next. $B_{\theta}^{*}$ captures this effect, and the model predicts a negative coefficient.

In the case of $B_{\theta}$, the point estimate for $1-\delta-\rho_{\theta}$ turns out to be very close to 0 , so that the level and time-trend effects cancel out almost exactly. We thus expect this coefficient to be close to 0 , and not very informative of over/underprovision of public capital.

For $B_{n}$, the confidence interval for $\rho_{n}$ still spans $1-\delta$, but a greater part lies in the range for which $1-\delta-\rho_{n}>0$. In this range, the time-trend effect dominates the level effect. Hence, when $x$ is such that public capital is overprovided (i.e., when the term inside brackets in (11) is negative), public investment responds less to population growth than it would if it simply kept

\footnotetext{
${ }^{18}$ The marginal debt financing that would make mobility a neutral force on the stock of public capital is about $81 \%$.
} 
up with providing infrastructure for the newcomers: $B_{n}<(1-\delta) / \delta \approx 15.7 .^{19}$

Figure 3 shows how our coefficients of interest depend on the fraction of debt financing. $B_{\theta}$ and $B_{\theta}^{*}$ cross the neutral level of 0 at $81 \%$ debt financing. The response of $B_{\theta}$ to changes in $x$ is more muted, since $1-\delta-\rho_{\theta}$ is close to zero. For values of $\rho_{\theta}<1-\delta$, $B_{\theta}$ would become increasing in $x . B_{n}$ crosses its neutral level of 15.7 at $84 \%$ debt financing. Since $\delta<1-\rho_{n}$, the time-trend effect dominates, and $B_{n}$ is decreasing in $x$ (i.e., overprovision is associated with a coefficient that is below the neutral level $(1-\delta) / \delta)$.

Figure 4 illustrates the role of the elasticity of the demand for the public good $\left(\sigma^{-1}\right)$. For small values of the elasticity, the provision of the public good does not respond much to the price as perceived by the voters, and the coefficients remain close to their neutral values, and far from those that we will estimate empirically. We choose $\sigma$ at the lower bound of the existing estimates to allow public good provision to respond in a meaningful way to our variables of interest.

Figure 5 displays the relationship between our coefficients of interest and the depreciation of public capital. In the case of the simple sum $B_{\theta}^{*}$, this relationship is straightforward. For low depreciation rates, $x=1$ leads to underprovision, and $B_{\theta}^{*}>0$. As $\delta$ increases, $B_{\theta}^{*}$ crosses zero and becomes more and more negative: for goods that are less and less durable, the benefits are more and more skewed towards the short run relative to the costs, and greater overprovision occurs. For $B_{n}$ and $B_{\theta}$, the relationship is more complex: over/underprovision interacts with the time trend/level effect. At very low depreciation rates, public capital is underprovided, and the time-trend effect dominates: hence $B_{n}>(1-\delta) / \delta$ and $B_{\theta}<0$. At high depreciation rates, public capital is overprovided, but the level effect dominates the trend effect, so $B_{n}$ and $B_{\theta}$ turn around and once again we have $B_{n}>(1-\delta) / \delta$ and $B_{\theta}<0$. This is why it is more difficult to rely on these measures to establish over/underprovision.

Finally, figure 6 shows how $B_{\theta}$ and $B_{\theta}^{*}$ are affected by the autocorrelation $\rho_{\theta}$. In the case of the simple sum $B_{\theta}^{*}$, this autocorrelation matters because it governs the rate at which future costs and benefits decay. A low autocorrelation implies that mobility reverts quickly, and voters

\footnotetext{
${ }^{19}$ Since $\rho_{n} \neq \rho_{\theta}$, the marginal debt financing that would make population growth a neutral force on the stock of public capital is not the same as that that would neutralize population growth. However, it is very similar, at about $84 \%$.
} 
respond less to its current deviations from the long-term mean, which means that $B_{\theta}^{*}$ is closer to 0 . In the case of the discounted sum, this interacts with the time-trend effect, that becomes dominant at low levels of correlation and thus implies $B_{\theta}>0$ even though our parameter values are such that public capital is overprovided.

\section{Data and Institutional Features of the States}

The assumptions in the model correspond to many of the basic features of state government finance in the United States. Nearly all states operate under the strictures of balanced budget requirements. These mandate that, at some point in the budgeting process, current expenditures are expected to be paid out of current revenues. States differ in when in the budget process balance must be obtained. As a result, these can differ in how binding they are in practice. For example, the Illinois constitution states, "The Governor shall prepare and submit to the General Assembly... a State budget for the ensuing fiscal year....Proposed expenditures shall not exceed funds estimated to be available for the fiscal year as shown in the budget." In Illinois, the legislature is also required to pass a balanced budget. However, if circumstances change within the fiscal year, the state can borrow to cover unexpected deficits.

Borrowing for capital expenditures lays outside these balanced budget requirements and separate provisions cover state ability to issue debt for capital projects. In Illinois, for example, the state can issue debt provided that it is for a specific purpose and is approved by $3 / 5$ of the legislature or by a majority of voters in a referendum. Nearly all states also have capital budgets that specifically detail how capital projects are to be financed.

For most municipal bonds, the state issues debt of a certain duration, gets the money up front, spends the money within 2-5 years of issuance, pays interest over time (usually semiannually) and then pays the entire principal back when the bond matures. Most municipal bonds are callable and most states allow bonds to be called and refunded provided that the duration is not extended. Municipal bonds tend to be of fairly long duration. In January 2011, the average maturity of municipal bonds was 15.6 years, while the average maturity of corporate 
bonds was 11.2 years. $^{20}$ Also in contrast to corporate bonds, one municipal bonds issuance often contains several maturities (these are called serial maturities). In addition, there are sinking funds associated with non-serial bonds where the issuer makes several payments into a sinking fund so that the entire principal does not need to be funded at one point. ${ }^{21}$

In order to estimate our model, our first need is to measure the flow variable $\gamma_{s t}$ for current and capital spending. For this purpose, we use data from the Annual Survey of State Government Finances. This data has been collected for all states by the Census Bureau since 1915 with the omission of some years in the 20s and 30s. Since 1952, the survey has followed a fairly consistent format. The data contain detailed information on government expenditures, revenues, and debt. State government expenditures are divided into 64 different government functions, such as Air Transportation, Corrections, and Elementary and Secondary Education. For each function, expenditure data is available for numerous different purposes such as capital expenditures, current expenditures, and intergovernmental expenditure.

In this paper we are concerned with patterns of current and capital expenditures. According to the survey's classification manual, current expenditures include expenditures for employee compensation, supplies and materials. By contrast, capital outlay includes "expenditure for purchase or construction, by contract or government employee, construction of buildings and other improvements; for purchase of land, equipment, and existing structures; and for payments on capital leases. ${ }^{22}$ " In the data, capital outlay is further divided into construction, purchase of land and existing structures, and purchase of equipment. We also separately measure nonhighway capital spending and non-highway construction spending, since Poterba [19] argues that highway spending is heavily influenced by federal transfers.

We supplement this with data on state population growth and state mobility. State population data is available annually from the Census Bureau. It is straightforward to calculate

${ }^{21}$ Our discussion here refers primarily to general obligation bonds, i.e., bonds that are guaranteed by the taxing power of the state. These bonds fit our theory better than revenue bonds, where the debt is repaid from revenues generated by the project; in this case, the state is essentially providing a private capital good. See Johnson and Rubin [15].

${ }^{22}$ See [26], chapter 5 .
} 
population growth rates, $n_{s t}$, from this data.

The measure of mobility delineated in the theory is the probability that a household living in state $s$ at $t$ is alive and in the same state at $t+1$. As mentioned earlier, we extrapolate away from death by assuming a constant hazard of death. Data on annual state to state migration are available from the IRS for 1975 to $2007 .{ }^{23}$ The IRS delineates a person as mobile if the address provided on their return one year is different from the address provided on their return the following year. We define a state's gross emigration rate as the number of people who provided an in-state address on last year's tax return and who provide an address in a different state this year, divided by the number of people who provided an in state address last year and still live in the US. The fraction of stayers is then one minus the gross emigration rate. We base this measure of stayers on the number of people who have stayed in state rather than the number of tax units that have stayed in state using information on the number of personal exemptions claimed. The IRS data does not include information on the mobility of individuals who do not file, or those who file after late September. We choose to use this data because it measures annual mobility as is suggested by the theory, is available since 1975 so provides us with a long time series, and is based on large enough samples to provide accurate measures of mobility for the smaller states. ${ }^{24}$

We can only consistently estimate $B_{\theta}^{*}, B_{\theta}$, and $B_{n}$ if the preference shock captured in $\epsilon_{s t}$ is orthogonal to population growth and immobility. As a result, we include in the regression features of states that we believe are correlated with spending and may be also correlated with either mobility or population growth. In particular we are concerned with proxying for state resident preferences for fiscal variables that may also be related to population growth or mobility. We choose several population attributes - average personal income, fraction of the population with a high-school diploma, fraction urban, population density, fraction over 65, fraction under

\footnotetext{
${ }^{23}$ We thank Alicia Sasser Modestino at the Federal Reserve Bank of Boston for sharing this data with us.

${ }^{24} \mathrm{We}$ also estimate our model based on five year migratory flows available in the Decennial Census. We interpolate between Census Years, adjust the estimates to account for the five year window, and forecast flows for years since the 2000 Census. We provide an estimate based on this alternative data in the appendix. The two measures are very highly correlated.
} 
25, homeownership rate, ${ }^{25}$ state size, population liberalism, and resident taste for mobility. Most of these variables are available annually or by decade from the Census Bureau. We interpolate between Census years for data that is not available yearly. Three measures merit further discussion - state size, population liberalism and resident taste for mobility. We measure a state's size in a given year as the fraction of U.S. population that lives in the state in that year. For population liberalism, we use factor analysis; specifically, we take the first factor from five state political variables - the percent of the popular vote for the Democratic Presidential candidate in the previous election, the percent of the state's Senate delegation that belongs to the Democratic Party, the percent of the state's House delegation that belongs to the Democratic party, the average Americans for Democratic Action (ADA; a liberal political organization) score for the state's Senate delegation, and the average ADA score for the state's House delegation. The resident taste for mobility is measured as the number of people that moved to a new house in the same state in the five years leading up to the Census divided by the number of people that stayed in state. We add this proxy for preferences for mobility because we believe that many unobservable attributes of populations that would influence interstate mobility would influence within-state mobility in a similar manner. ${ }^{26}$

Variable means and our abbreviations for these variables are presented in Table 2. We can see from this table that states vary substantially in per capita fiscal variables. We also note that state current spending is about 8 times the level of state capital spending on average. Most capital spending is for construction while smaller amounts are dedicated to land and equipment expenditure.

\section{Estimation}

To assess the success and the shortcomings of the model in explaining the data, we proceed in two steps. First, we completely parameterize the model imposing plausible values into equation

\footnotetext{
${ }^{25}$ The homeownership rate is defined as the fraction of houses that are owner-occupied.

${ }^{26}$ State size would be an important exception, which is why we included it as an explicit control. Results are similar with or without introducing state size.
} 
(9), and we study the dimensions in which the results diverge from the data. These parameter values are summarized in Table 1. Second, we give the model one degree of freedom and use estimates of $B_{n}, B_{\theta}$, and $B_{\theta}^{*}$ to infer the amount of debt financing allowed at the margin $(x)$, while holding all other parameters at their calibrated values. This gives us an alternative measure of the aspects of the data that the model is able to capture, and those that it misses.

Two remarks are worth noting about estimating (10):

- Estimates of the individual coefficients in the sums will be imprecise, due to the high autocorrelation and the resulting collinearity. However, we are interested in sums of these coefficients, and those will still be precisely estimated.

- Although in theory the formulas (11), (12), and (13) work for any $J \geq k+1$, since all terms in the sum should be zero for $j>k+1$, the exponential term $\rho^{-j}$ implies that estimates would become very imprecise for large $J$. It is thus in practice important to choose a parsimonious number of lags. We work with 4 lags, which implies that we assume that public goods have an implementation delay of no more than 3 years.

We start our empirical analysis with a simple regression that predicts the natural log of per capita fiscal variables based on contemporaneous population growth, mobility, and year dummies alone. $^{27}$ We cluster the standard errors by state. The results are presented in Table 3. Two clear facts emerge from this table: ${ }^{28}$

- Population growth is very weakly related to state-level spending; and

- the higher the fraction of stayers in a state (i.e., the smaller the gross emigration rate), the smaller is spending: a one standard deviation increase in the fraction of stayers increases log capital spending per capita by approximately $2 / 3$ of a standard deviation.

For the purpose of reconciling the evidence with the theory, it is interesting to see that both facts are least pronounced in the case of purchases of land and existing structures, arguably the most

\footnotetext{
${ }^{27}$ In the case of purchases of land and existing structures we lose two state-year observations due to zeros.

${ }^{28}$ These facts match what was found by Poterba [19] in his cross-sectional analysis of state-level spending in 1962; see his Table 1.
} 
durable category of state spending. For this variable, a positive (but statistically insignificant) association emerges with population growth, and the negative association with the fraction of stayers is smallest and not statistically significant.

Our identifying restriction is that the preference shock in (9) is uncorrelated with population growth and mobility. In our preferred regression, we introduce several controls that are meant to capture elements of the preference shock that may be correlated with demographics.

In Table 4, we run the same regression, but including all of our baseline controls. The inclusion of controls only modestly affects the coefficient on the fraction of stayers. For population growth, coefficients move from being weakly negative to weakly positive, but still much smaller than what is needed to keep constant the amount of capital per capita (which would be $(1-\delta) / \delta$ ). Our main conclusions are thus largely unchanged. It is particularly noteworthy that the correlation between emigration and state-level spending is not due to a general inclination to mobility by the residents of a state: our regressions show that more internal migration within a state is associated with less spending. Aside from internal mobility, we find that states with richer populations spend more on capital goods. We also find that states with younger populations spend more on capital projects. This may be explained by the large role of states in the purchase and construction of school buildings. Our political variable shows that capital spending does not appear to be a partisan issue, whereas more liberal states have higher current expenses. Finally, there is some evidence that urbanization is associated with less state-level spending.

In Table 5, we present results from the regression that best matches the theory. We assume that public investment takes at most 3 years from the moment it is approved, which calls for using the contemporaneous value and 4 lags of population growth and mobility, ${ }^{29}$ and calls for lagging controls by 3 years. ${ }^{30}$ The table displays both discounted and undiscounted sums

\footnotetext{
${ }^{29}$ The time dimension in our panel regression spans 28 years, which should be long enough to avoid the shortsample bias in estimating dynamic responses. In any case, our main interest is in the sum of the coefficients and not in identifying the precise lag correlation of spending with population growth and mobility.

${ }^{30}$ In equation (9), the most recent preference shock that should matter is given by $E_{t-k} \phi_{s t}$, i.e., it is based on information $k$ years in the past. For goods for which $k<3$, the 3-year lag of the control variable can be viewed as an instrument for the $k$-year lag. In practice, all of our controls are very autocorrelated, and the number of lags in the regression makes little difference.
} 
of the coefficients on population growth and the fractions of stayers: these sums confirm the weak connection between population growth and capital spending, and the negative relationship between stayers and capital spending.

The tables in the appendix show that our results are robust along several dimensions. First, we combined state and local spending to check that our results are not driven by differences across states in the level of government that provides services. Our coefficients of interest remain very similar, while there are changes in the coefficients for some of the controls. In particular, we find that internal migration and urbanization are no longer statistically significant predictors of spending. Second, in his study of U.S. counties, Rappaport [20] argues that there are endogenous population movements towards small-government areas. His theory suggests that net migration responds to government size. To ensure that our results are not driven by reverse causality, we include a measure of net migration. This added variable has little effect on the large negative coefficients for stayers, the relevant measure for our model, which is equal to one minus gross migration. ${ }^{31}$ Including net migration in our regressions also does not significantly alter our conclusions about the relationship of capital spending with population growth. Net migration itself is weakly related to capital spending. Our data support Rappaport's theory in that we find a significant negative coefficient on net migration in the current spending regression. Third, we confirmed that our results are robust to including the measure of political competition from Besley, Persson, and Sturm [11], ${ }^{32}$ since they find that it is a predictor of the mix of spending by states. Finally, we look at the relationship between population growth, mobility, and spending within states over time by including state fixed effects. This modestly attenuates the effect of mobility and increases the predictive power of population growth, but it does not substantively alter our conclusions.

To see how the results in Table 5 square with the model, we need estimates of $\rho_{n}$ and $\rho_{\theta}$. For

\footnotetext{
${ }^{31}$ The correlation between stayers and net migration in our sample is low and negative: states where population is churning in and out have a weak tendency to attract more residents.

${ }^{32}$ We are indebted to Torsten Persson for sharing their measure.
} 
population growth, our estimate from the data yields:

$$
n_{s t}=\underset{(0.000384)}{0.00121}+\underset{(0.0395)}{0.875} n_{s t-1} \text { +error term }
$$

For mobility, we have:

$$
\theta_{s t}=\underset{(0.00738)}{0.0396}+\underset{(0.00764)}{0.959} \theta_{s t-1} \text { +error term }
$$

Table 6 uses the results from Table 5 to compute estimates of $B_{n}, B_{\theta}$, and $B_{\theta}^{*}$, and compares them with the values predicted by the calibrated model, if we assume that $100 \%$ of capital spending is financed with debt at the margin, and none of current spending (the "golden rule"). For general capital, we use the baseline calibration of Table 1; for its subcategories, we use different values of $\delta: \delta=0.02$ for purchases of land and existing structures, $\delta=0.15$ for equipment, and $\delta=0.05$ for construction. In the case of current expenses, we set $\delta=1$ (full depreciation). The model prediction depends on the estimates of the autocorrelation coefficients; we incorporate this uncertainty by presenting a range based on the $95 \%$ confidence interval. ${ }^{33}$

Looking at mobility first, the model calibration implies that $100 \%$ borrowing is more than what is needed to restore appropriate incentives for total capital expenditure, and hence that the fraction of stayers in the state should have a negative effect on capital provision (by bringing the economy closer to Ricardian equivalence and thus curtailing overspending). As is noted in Inman [14] and Poterba [19], states with high mobility can use debt issuance to transfer the funding of capital projects to future residents and therefore may demand more spending. While current residents get some of the benefits of the capital spending now, future residents pay. The estimate of $B_{\theta}^{*}$ from the data is indeed negative, supporting the qualitative conclusion of the

\footnotetext{
${ }^{33}$ In the case of the model, we obtain the implied range evaluating the expressions for each value of $\rho_{n}$ and $\rho_{\theta}$ in their $95 \%$ confidence interval, and taking the maximum and minimum of the result. With one exception (land and population growth), our coefficients are monotone in $\rho_{n}$ or $\rho_{\theta}$, so the maximum and minimum are attained at the extremes of the confidence interval. For the standard deviation of our estimated coefficients, we combine uncertainty about the autocorrelation and about each underlying parameter in the sums (11), (12), and (13) using the delta method.
} 
model, but its magnitude is too big, even allowing a high elasticity of demand for the public good. In the data, mobility is even more important than our model would suggest. This is even more true for the discounted sum $B_{\theta}$, which according to theory should be slanted towards 0 , while it is not in the data. If we exclude highway spending, where federal transfers play a major role, the estimated effect of mobility is still high, but now the confidence interval for our estimates has significant overlap with the range from the theory. Columns (3) through (6) break down total capital spending into its components. They highlight that our miss occurs in construction expenditures: we would expect small coefficients from the theory, since these are fairly durable expenses and overprovision should be small, but the estimates from the data are actually biggest. The theory captures well the role of purchases of land and existing structures: for these very durable expenses, even $100 \%$ borrowing is not sufficient according to our calibration, and a higher fraction of stayers (in its level effect captured by $B_{\theta}^{*}$ ) should increase spending. This is the only component for which the data show no significant negative relationship with the fraction of stayers. In the case of current expenses, strict adherence to the golden rule makes mobility and spending independent in the model. Our estimates suggest instead a negative and significant relationship. As we will show below, these coefficients can be justified by the theory if states are able to finance some of their current expenditures with debt, so we regard this miss as evidence that states have some leeway to evade the strictures of the golden rule.

The model predictions about population growth are weaker, because of the offsetting level and time-trend effects. The model predicts small, but positive coefficients, reflecting the need for additional investment when population is growing. The data show an insignificant negative relationship, and there is a large overlap between the range dictated by theory and the confidence intervals of the estimates. One notable exception is for the most durable category of purchases of land and existing structures. Here, the theory suggests a very large and positive coefficient. Since these are very durable expenses, the flow spending needed to keep up with depreciation is small relative to the stock, and keeping a constant level per capita when population grows faster requires a much bigger percentage increase in investment. On top of this, the theory predicts underspending in this category of purchases, since more than $100 \%$ debt would be needed (or 
a longer maturity of debt). The time-trend effect (which dominates the level effect) boosts this coefficient further. We do observe evidence of a positive relationship in the data, although it is imprecisely estimated and it is not as strong as the prediction of the theory.

In the previous analysis no parameter of the model was allowed to vary based on our empirical findings. We next give the model one degree of freedom by inferring values of $x$ from our regression results, while keeping all other parameters fixed. Specifically, we look for the values of $x$ that can match the regression coefficients to those implied by the model. We first present results from matching each of $B_{n}, B_{\theta}$, and $B_{\theta}^{*}$ independently. We then obtain a GMM estimate based on the 3 moments, and test the two overidentifying restrictions.

Table 7 presents our results. ${ }^{34}$

As can be seen from equations (11) and (12), when autocorrelation is close to $1-\delta$ the coefficients $B_{n}$ and $B_{\theta}$ are not very sensitive to the fraction of debt financing $x$. Since our estimates are based on inverting this relationship, in this case the implied value of $x$ is extremely sensitive to autocorrelation, and it cannot be reliably inferred, resulting in standard errors so large that no meaningful conclusion can be drawn. For inference based on $B_{n}$, this is particularly an issue for equipment expenses (since $\rho_{n} \approx 0.88$ and $\delta=0.15$ ); for $B_{\theta}$, this affects total expenditures, with or without highways $\left(\rho_{\theta} \approx 0.96\right.$ and $\left.\delta=0.06\right)$ and especially construction $(\delta=0.05)$.

For the cases in which reliable estimates can be derived from a single moment condition, the table shows once again that the response of capital spending to population growth and mobility (columns 1 through 5) is stronger in the data than we would expect in the model. In most cases, it would take more than $100 \%$ debt financing of capital expenses to justify the response we observe in the data. Using all 3 moments jointly results in estimates that are generally closer to $100 \%$ debt financing; ${ }^{35}$ we can reject $x=1$ for equipment and land, and marginally for construction.

\footnotetext{
${ }^{34}$ In computing the standard deviation, we assume independence of the errors from the regressions used to estimate the autoregression coefficients from those of the regressions that estimate the response of government spending to our variables of interest.

${ }^{35}$ It may at first be surprising that the estimate based on the 3 moments jointly is not a convex combination of the estimates based on the individual moments. This is a natural consequence of the fact that the three moment conditions are not independent. For two positively correlated random variables, if we observe one to be below its
} 
Except for land expenditures ${ }^{36}$ our tightly parameterized model is still statistically rejected by the data, but the magnitude of the P-values suggests that it would not take a major perturbation to be able to reconcile the response of spending to population growth and mobility.

Column 7 presents the results for current expenditures. The values of $x$ that are consistent with the coefficients on mobility are positive and statistically significant, and the same happens for the GMM estimate. This conforms well with the idea that the golden rule is not completely successful at preventing states from borrowing to pay for these expenses, and that some leeway remains.

\section{Conclusion}

We begin with an explicit political economy model where population growth and mobility lead to departures from Ricardian equivalence. In our model, population dynamics cause voters to discount the future more heavily than efficiency would dictate. We derive a testable prediction that, in the presence of high degrees of debt financing, we should observe a positive relationship between capital spending and mobility for rapidly depreciating capital goods and a negative relationship for slowly depreciating assets. Our results are supportive of this prediction, but we find that greater mobility is associated with higher capital spending to a somewhat greater degree than can be explained by the theory.

Our results suggest two avenues of future research. First, if mobility and capital spending are related in the way we highlight in the paper, individual-level expectations of mobility should be predictive of individual voting behavior; this could be tested with more disaggregated political data, particularly for debt referenda.

Second, our evidence suggests that some of the costs of current state expenditures are shifted to future residents despite restrictions on the issuance of debt for current expenditure. How states do so in practice is an interesting question. One area of current expenditure that deserves unconditional mean, we expect the second one to also be below its unconditional mean.

${ }^{36}$ Interestingly, land, along with current expenditures, is the only case for which all estimates from individual moments are fairly reliable. 
further scrutiny is the treatment of pension obligations. As is noted by Inman [14], while current residents benefit from the services provided by current workers, if pensions and other benefits are underfunded, future residents will bear some of the cost. Current residents therefore have an incentive to underfund pensions. Exploring the theoretical and empirical relationship between population dynamics and pension funding could be analyzed with a similar type of model.

\section{References}

[1] Marina Azzimonti. Barriers to Investment in Polarized Societies. American Economic Review, 2011. forthcoming.

[2] Marina Azzimonti, Marco Battaglini, and Stephen Coate. On the Case for a Balanced Budget Amendment to the U.S. Constitution. Mimeo, Princeton University, 2008.

[3] Ruediger Bachmann and Jinhui Bai. Government Purchases over the Business Cycle: the Role of Economic and Political Inequality. Working Paper 8539, NBER, 2010.

[4] Robert J. Barro. Are Government Bonds Net Wealth? Journal of Political Economy, 82:1095-1117, 1974.

[5] Marco Bassetto. Public Investment and Budget Rules for State vs. Local Governments. Working Paper 21, Federal Reserve Bank of Chicago, 2008.

[6] Marco Bassetto and Vadym Lepetyuk. Government Investment and the European Stability and Growth Pact. Federal Reserve Bank of Chicago Economic Perspectives, 31(3):33-43, 2007.

[7] Marco Bassetto with Thomas J. Sargent. Politics and Efficiency of Separating Capital and Ordinary Government Budgets. Quarterly Journal of Economics, 121(4):1167-1210, 2006.

[8] Marco Battaglini and Stephen Coate. Inefficiency in Legislative Policy-Making: A Dynamic Analysis. American Economic Review, 97(1):118-149, 2007. 
[9] Marco Battaglini and Stephen Coate. A Dynamic Theory of Public Spending, Taxation, and Debt. American Economic Review, 98(1):201-236, 2008.

[10] Marco Battaglini and Stephen Coate. Fiscal Policy over the Real Business Cycle: A Positive Theory. Working Paper 14047, NBER, 2008.

[11] Timothy Besley, Torsten Persson, and Daniel M. Sturm. Political competition, policy and growth: Theory and evidence from the United States. Review of Economic Studies, $77(4): 1329-1352,2010$.

[12] Alison F. DelRossi and Robert P. Inman. Changing the Price of Pork: the Impact of Local Cost Sharing on Legislators' Demands for Distributive Public Goods. Journal of Public Economics, 71(2):247-273, 1999.

[13] Jonah B. Gelbach. Migration, the Life Cycle, and State Benefits: How Low Is the Bottom? Journal of Political Economy, 112(5):1091-1130, 2004.

[14] Robert P. Inman. Public Employee Pensions and the Local Labor Budget. Journal of Public Economics, 19(1):49-71, October 1982.

[15] Craig Johnson and Marilyn Marks Rubin. The Municipal Bond Market: Structure and Changes. In Fred Thompson and Mark T. Green, editors, Handbook of Public Finance, pages 483-522. Marcel Dekker Inc., 1998.

[16] John Kennan and James R. Walker. The Effect of Expected Income on Individual Migration Decisions. Econometrica, 79(1):211-251, 2011.

[17] Paul Klein, Per Krusell, and José-Víctor Ríos-Rull. Time Consistent Public Policy. Review of Economic Studies, 75(3):789-808, 2008.

[18] Bruce D. Meyer. Do the Poor Move to Receive Higher Welfare Benefits? Joint Center for Poverty Research Working Paper, 58, 2000. Northwestern University/ University of Chicago.

[19] James M. Poterba. Capital Budgets, Borrowing Rules, and State Capital Spending. Journal of Public Economics, 56(2):165-187, 1995. 
[20] Jordan Rappaport. Local Growth Empirics. Working Paper 23, Harvard University, Center for International Development, 1999.

[21] Stephen Ross and John Yinger. Sorting and voting: A review of the literature on urban public finance. In J. Vernon Henderson and Jacques-François Thisse, editors, Handbook of Regional and Urban Economics. Volume 3, chapter 47, pages 2001-2060. Elsevier Science, North Holland, 1999.

[22] Securities Industry and Financial Markets Association (SIFMA). U.S. Corporate Bond Average Maturity. www.sifma.org, 2011. Available under Research - Statistics.

[23] Securities Industry and Financial Markets Association (SIFMA). U.S. Municipal Bonds Average Maturity. www.sifma.org, 2011. Available under Research - Statistics.

[24] Zheng Michael Song, Kjetil Storesletten, and Fabrizio Zilibotti. Rotten Parents and Disciplined Children: A Politico-Economic Theory of Public Expenditure and Debt. Working Paper 325, Institute for Empirical Research in Economics, University of Zurich, 2007.

[25] Paul Studensky. Public Borrowing. National Municipal League, 1930.

[26] U.S. Census Bureau. Government Finance and Employment Classification Manual. http:// www. census.gov/govs/www/06classificationmanual/06_gfe_classmanual_toc.html, 2006. 


$\begin{array}{lll}\text { Parameter } & \text { Assigned Value } & \text { Comment } \\ \beta & 0.96 & \\ \delta & 0.06 & \\ \alpha & 1-2^{-1 / 15} \approx 0.045 & \text { Half-life of debt: } 15 \text { years } \\ \rho_{n} & 0.875 & \text { Estimate from data } \\ \rho_{\theta} & 0.959 & \text { Estimate from data } \\ \sigma & 0.2 & \text { Lower range of estimates surveyed by DelRossi and Inman }[12] \\ x & 1 & 100 \% \text { debt financing allowed for capital projects } \\ k & 2 & \text { Typical implementation delay (years) }\end{array}$

Table 1: Baseline calibration 
Variable

Total capital spending (\$)

Non-highway capital spending (\$)

Land and purch. of existing structures (\$)

Equipment purchases (\$)

Construction spending (\$)

Non-highway construction spending (\$)

Current expenditures (\$)

Population growth (yearly)

Fraction staying in state (1-yr horizon)

Fraction moving within state (5-yr horizon)

State personal income (\$ thousands)

Fraction high-school graduates

Fraction population urban

Pop. density (thousands per sq. mile)

Fraction of population over the age of 65

Fraction of population under the age of 25

Homeownership rate

Liberalism index

Fraction of U.S. population living in state

$\begin{array}{lcccc}\text { Label } & \text { Mean } & \text { St. Dev. } & \text { Min } & \text { Max } \\ \text { TOTCAP } & 340.7 & 211.6 & 85.7 & 2367.5 \\ \text { NHCAP } & 140.7 & 132.3 & 28.5 & 1724.5 \\ \text { LAND } & 18.60 & 24.13 & 0 & 437.76 \\ \text { EQUIP } & 44.60 & 27.08 & 5.15 & 305.69 \\ \text { CONSTR } & 277.5 & 182.7 & 47.6 & 2142.5 \\ \text { NHCONSTR } & 93.31 & 105.65 & 8.45 & 1308.94 \\ \text { CURRENT } & 2711 & 1259 & 1031 & 13810 \\ \text { POPGR } & 0.01075 & 0.01140 & -0.05722 & 0.08632 \\ \text { STAY } & 0.9661 & 0.0129 & 0.8688 & 0.9846 \\ \text { INTMIG } & 0.3769 & 0.04461 & 0.2599 & 0.5240 \\ \text { STATEINC } & 27.91 & 6.74 & 14.2 & 55 \\ \text { EDU } & 0.7747 & 0.0975 & 0.4726 & 0.93 \\ \text { URBAN } & 0.6960 & 0.1471 & 0.322 & 0.9503 \\ \text { DENSITY } & 0.1433 & 0.1859 & 0.0006 & 0.9903 \\ \text { OVER65 } & 0.1208 & 0.0216 & 0.0230 & 0.1855 \\ \text { UNDER25 } & 0.3780 & 0.0393 & 0.2974 & 0.5248 \\ \text { HOMEOWN } & 0.6752 & 0.0548 & 0.4808 & 0.813 \\ \text { LIB } & 0 & 0.9426 & -2.0404 & 2.0234 \\ \text { SIZE } & 0.02 & 0.02148 & 0.00172 & 0.12166\end{array}$

Table 2: Summary statistics. All monetary values are expressed in per capita $2007 \$$. 


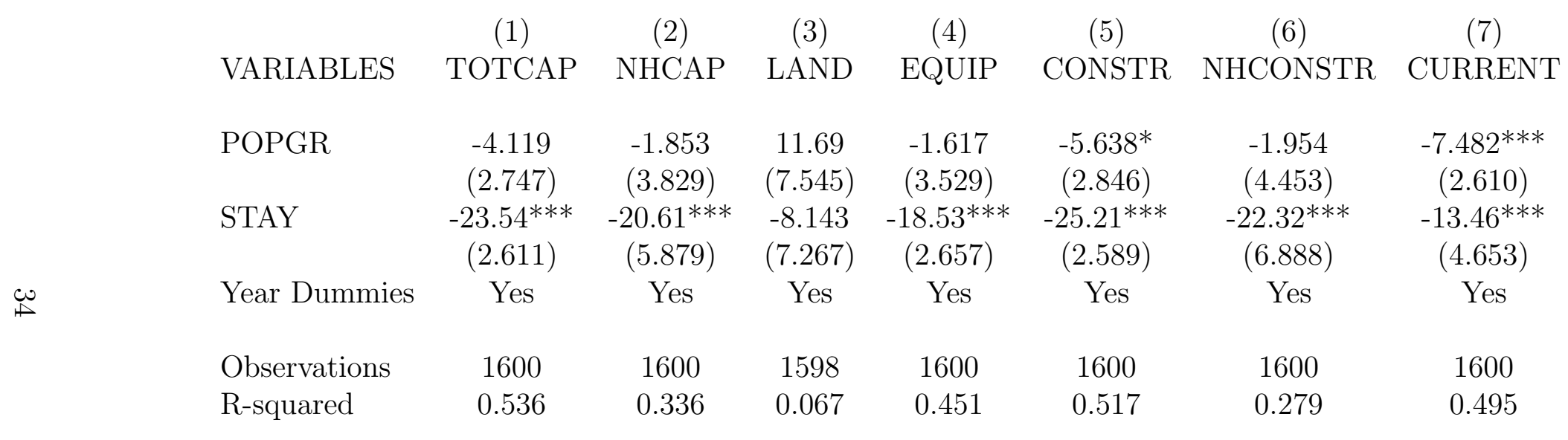

Table 3: Regression of spending on population growth and the fraction of stayers, with no controls and no lags. Year dummies are included, and standard errors are clustered at the state level. Significance is indicated at the $1 \%$ (***), 5\% $\left(^{* *}\right)$, and $10 \%(*)$ levels. 


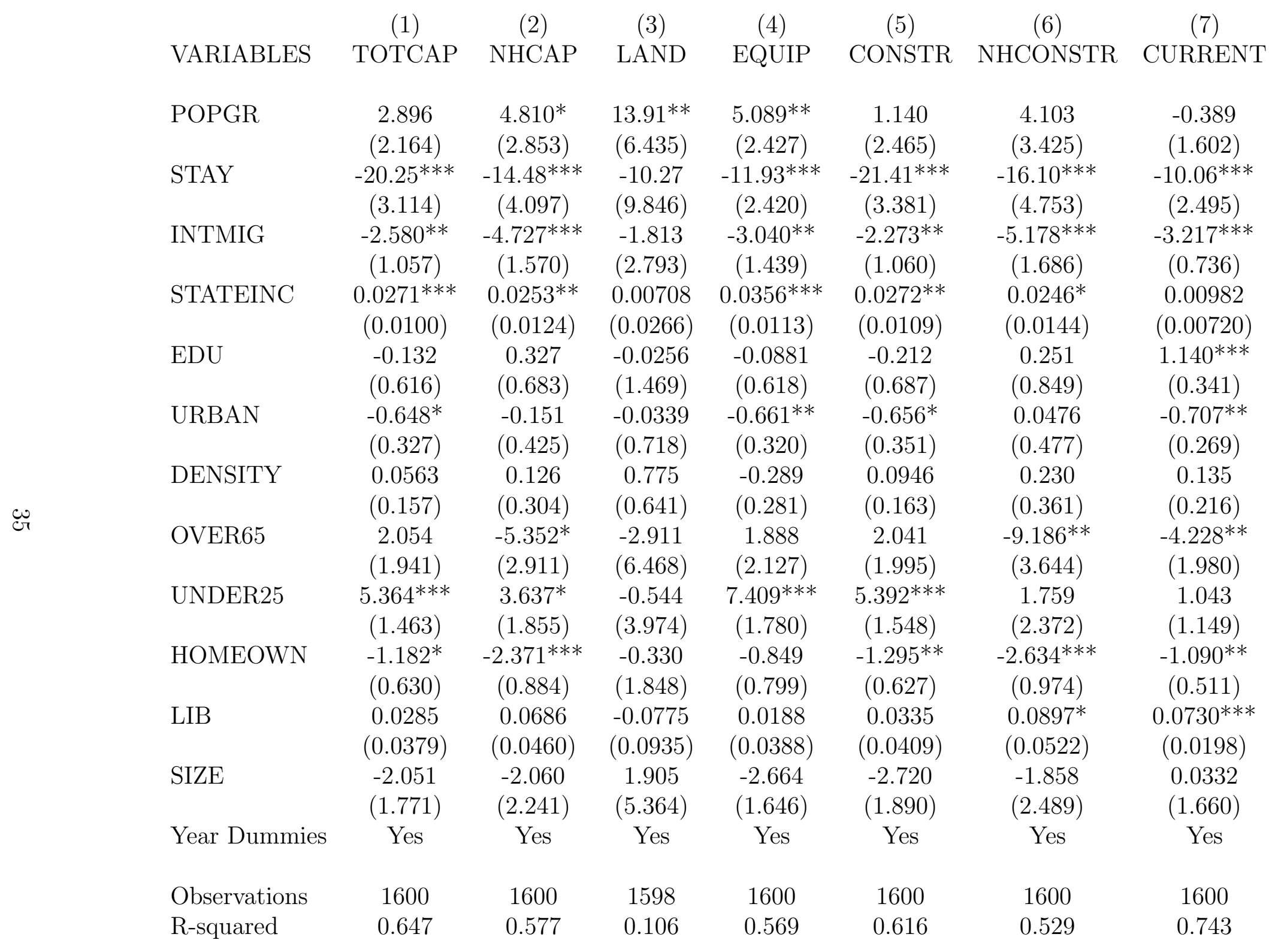

Table 4: Regression of spending on population growth and the fraction of stayers, including controls but no lags. Year dummies are included, and standard errors are clustered at the state level. Significance is indicated at the $1 \%$ (***), 5\% $(* *)$, and $10 \%(*)$ levels. 


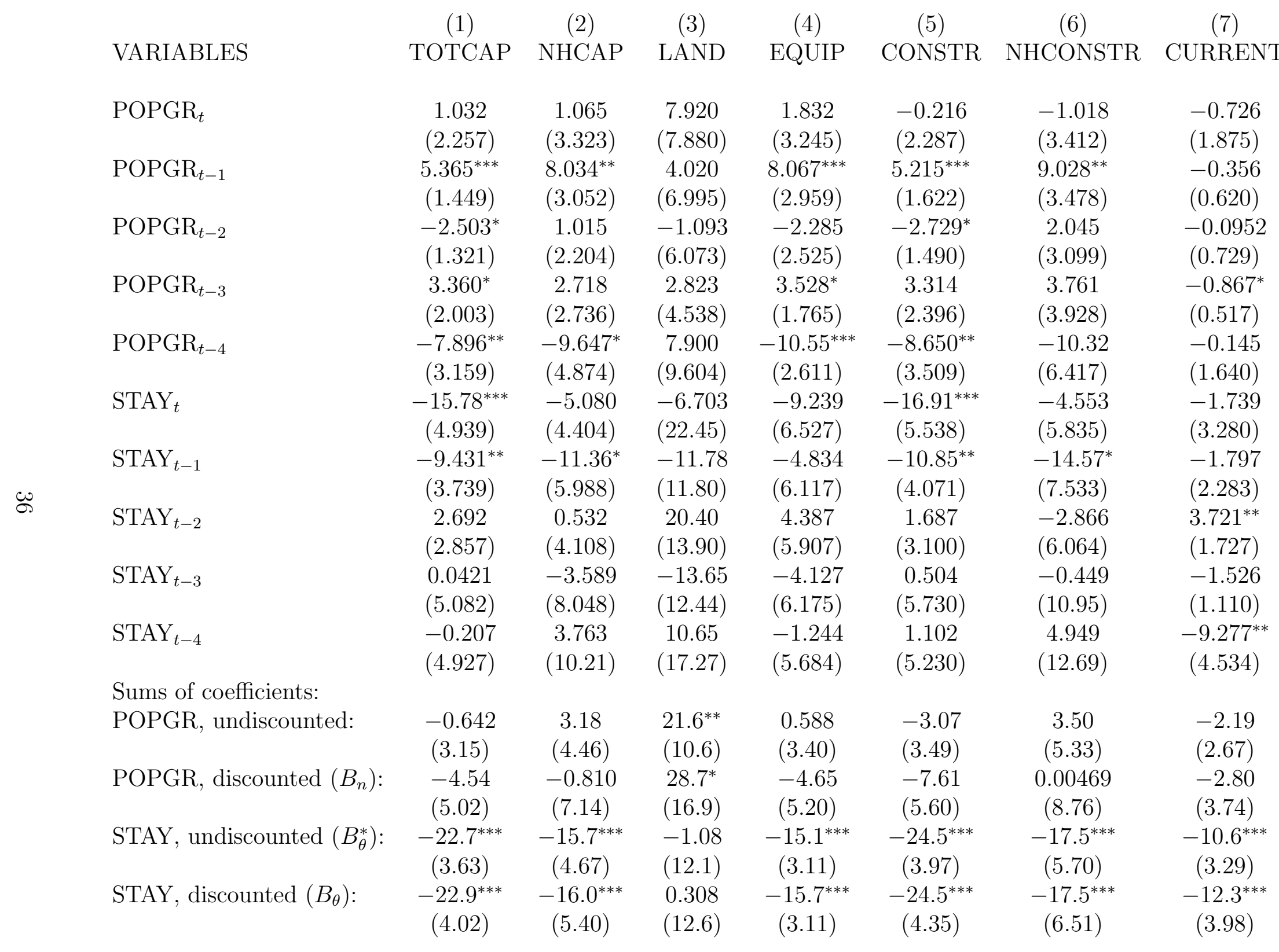

Table 5: Continued on the next page 


$\begin{array}{lccccccc} & (1) & (2) & (3) & (4) & (5) & (6) & (7) \\ \text { VARIABLES } & \text { TOTCAP } & \text { NHCAP } & \text { LAND } & \text { EQUIP } & \text { CONSTR } & \text { NHCONSTR } & \text { CURRENT } \\ & & & & & & & \\ \text { INTMIG } & -1.867 & -4.165^{* *} & -1.446 & -3.085^{*} & -1.415 & -4.481^{* *} & -3.070^{* * *} \\ & (1.180) & (1.728) & (2.981) & (1.554) & (1.190) & (1.900) & (0.770) \\ \text { STATEINC } & 0.0272^{* *} & 0.0306^{* *} & 0.0219 & 0.0315^{* * *} & 0.0273^{* *} & 0.0297^{*} & 0.0116 \\ & (0.0120) & (0.0148) & (0.0256) & (0.0117) & (0.0130) & (0.0176) & (0.0104) \\ \text { EDU } & -0.0190 & 0.363 & -0.242 & 0.135 & -0.106 & 0.432 & 1.047^{* * *} \\ & (0.640) & (0.713) & (1.529) & (0.626) & (0.722) & (0.906) & (0.365) \\ \text { URBAN } & -0.624^{*} & -0.224 & -0.261 & -0.552 & -0.625^{*} & -0.0692 & -0.745^{* *} \\ & (0.349) & (0.471) & (0.810) & (0.339) & (0.371) & (0.548) & (0.308) \\ \text { DENSITY } & 0.219 & 0.240 & 0.767 & -0.200 & 0.275 & 0.397 & 0.203 \\ & (0.167) & (0.328) & (0.663) & (0.272) & (0.174) & (0.405) & (0.225) \\ \text { OVER65 } & 2.451 & -4.643 & -1.399 & 1.500 & 2.455 & -8.495^{* *} & -3.903^{* *} \\ & (1.891) & (2.890) & (6.980) & (1.951) & (1.947) & (3.759) & (1.794) \\ \text { UNDER25 } & 5.432^{* * *} & 4.410^{* *} & 1.322 & 6.873^{* * *} & 5.428^{* * *} & 2.698 & 1.203 \\ & (1.512) & (2.013) & (4.856) & (1.704) & (1.624) & (2.660) & (1.400) \\ \text { HOMEOWN } & -1.101 & -2.216^{* *} & -1.322 & -1.078 & -1.132^{*} & -2.328^{* *} & -1.181^{* *} \\ & (0.678) & (0.901) & (1.987) & (0.897) & (0.672) & (1.017) & (0.507) \\ \text { LIB } & 0.0222 & 0.0665 & -0.0857 & 0.0109 & 0.0288 & 0.0924^{*} & 0.0685^{* * *} \\ & (0.0390) & (0.0459) & (0.100) & (0.0402) & (0.0420) & (0.0519) & (0.0210) \\ \text { SIZE } & -1.637 & -1.495 & -1.269 & -1.560 & -2.194 & -0.955 & 0.361 \\ & (1.853) & (2.265) & (5.723) & (1.770) & (1.958) & (2.535) & (1.621) \\ \text { Year Dummies } & \text { Yes } & \text { Yes } & \text { Yes } & \text { Yes } & \text { Yes } & \text { Yes } & \text { Yes } \\ \text { Observations } & 1400 & 1400 & 1398 & 1400 & 1400 & 1400 & 1400 \\ \text { R-squared } & 0.636 & 0.574 & 0.106 & 0.539 & 0.610 & 0.532 & 0.752\end{array}$

Table 5: Regression of spending on population growth and the fraction of stayers and their lags, including controls. Year dummies are included, and standard errors are clustered at the state level. Significance is indicated at the $1 \%(* * *), 5 \%(* *)$, and $10 \%(*)$ levels. 
(1) Spending

$B_{n}$

Data:

Model:

-4.54
$(5.02)$

$-1.3-17.9$

-0.81
$(7.14)$
$-1.3-17.9$

(3)

Land and Purchases of Existing

Structures

\section{7}

Less Highways
(6)

Construction

Less Highways
VARIABLES Total Capital Total Capital

(5)

$B_{\theta}$

Data:

Model:

-22.9
$(4.02)$
$-6.6--0.7$

$$
\begin{gathered}
-16.0 \\
(5.40) \\
-6.6--0.7
\end{gathered}
$$

(16.9)

$59-71$

-4.65
$(5.20)$
$1.1-23.2$

$-15.7$

(3.11)

(12.6)

$-16.7--3.9$

$-24.8--15.2$

-1.08
$(12.1)$
$7.9-12.6$

-15.1
$(3.11)$
$27.7--20.4$
$-7.61$
$(5.60)$

$1.4-19.4$

$$
\begin{gathered}
0.005 \\
(8.76) \\
1.4-19.4
\end{gathered}
$$

0

$-12.3$

$\begin{array}{cc}(4.35) & (6.51) \\ -3.6-0.8 & -3.6-0.8\end{array}$

Model:

$$
-10.8--8.5
$$$$
-10.8--8.5
$$

$7.9-12.6$

$$
\begin{gathered}
-17.5 \\
(5.70) \\
-6.8--5.7
\end{gathered}
$$
xpenditures

Table 6: Comparison of coefficients of interest in the regression with their predicted values according to the baseline calibration of our model, assuming that state governments follow the golden rule. 


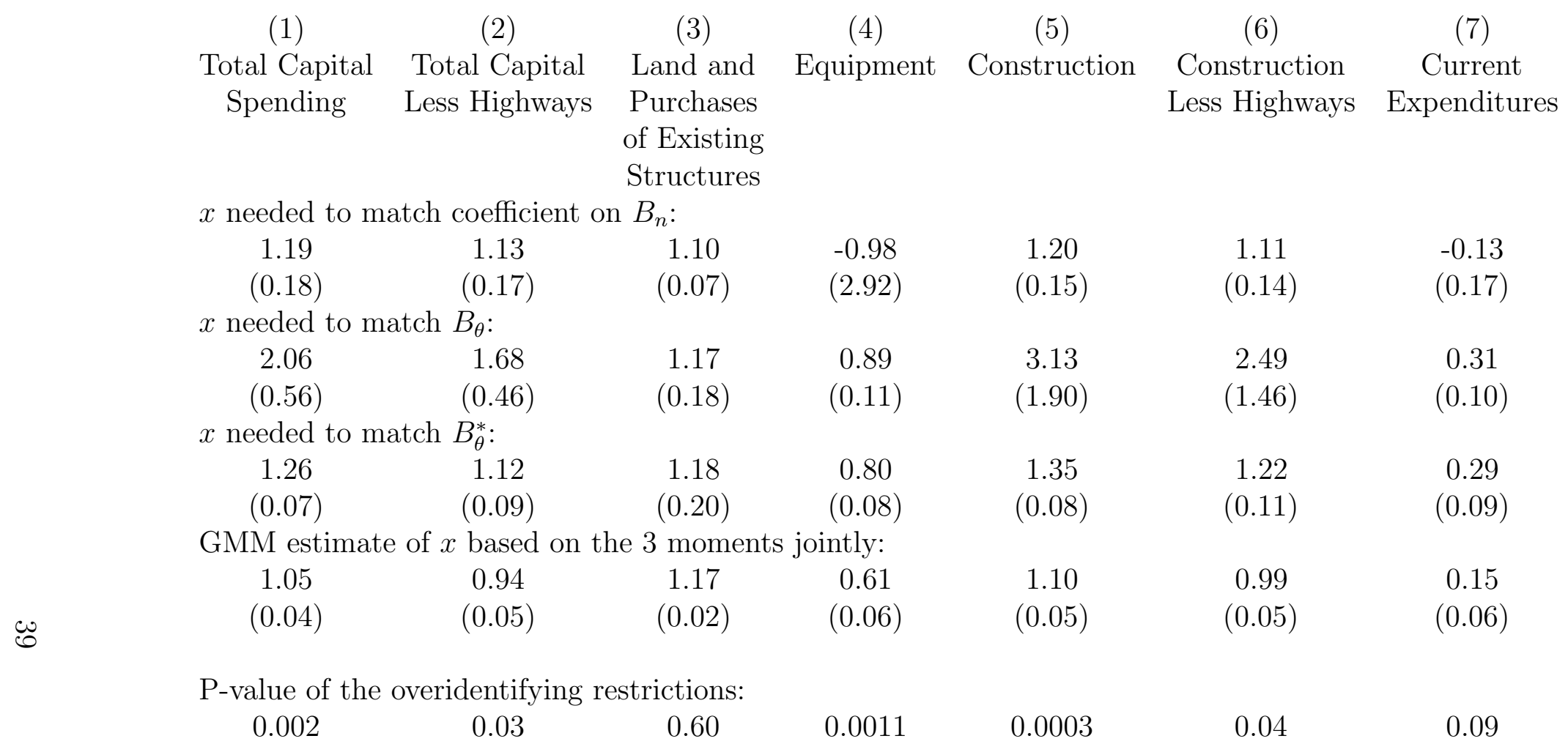

Table 7: Indirect estimates of the fraction of debt financing derived from estimates of $B_{n}, B_{\theta}$, and $B_{\theta}^{*}$, and test of the overidentifying restriction that they are equal to each other. 


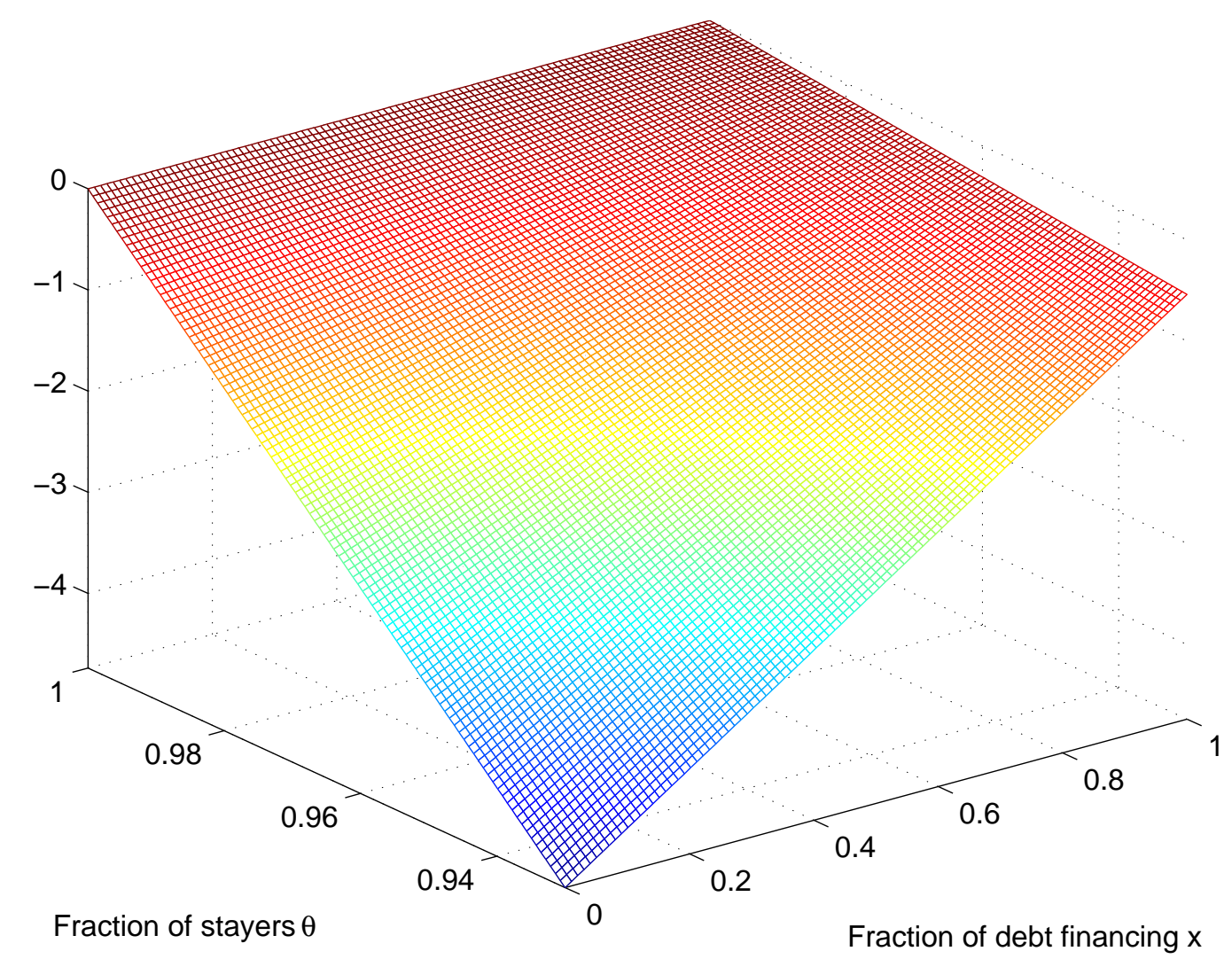

Figure 1: Logarithm of public good provision with no pop. growth and constant mobility rate, $\delta=0.03$. 


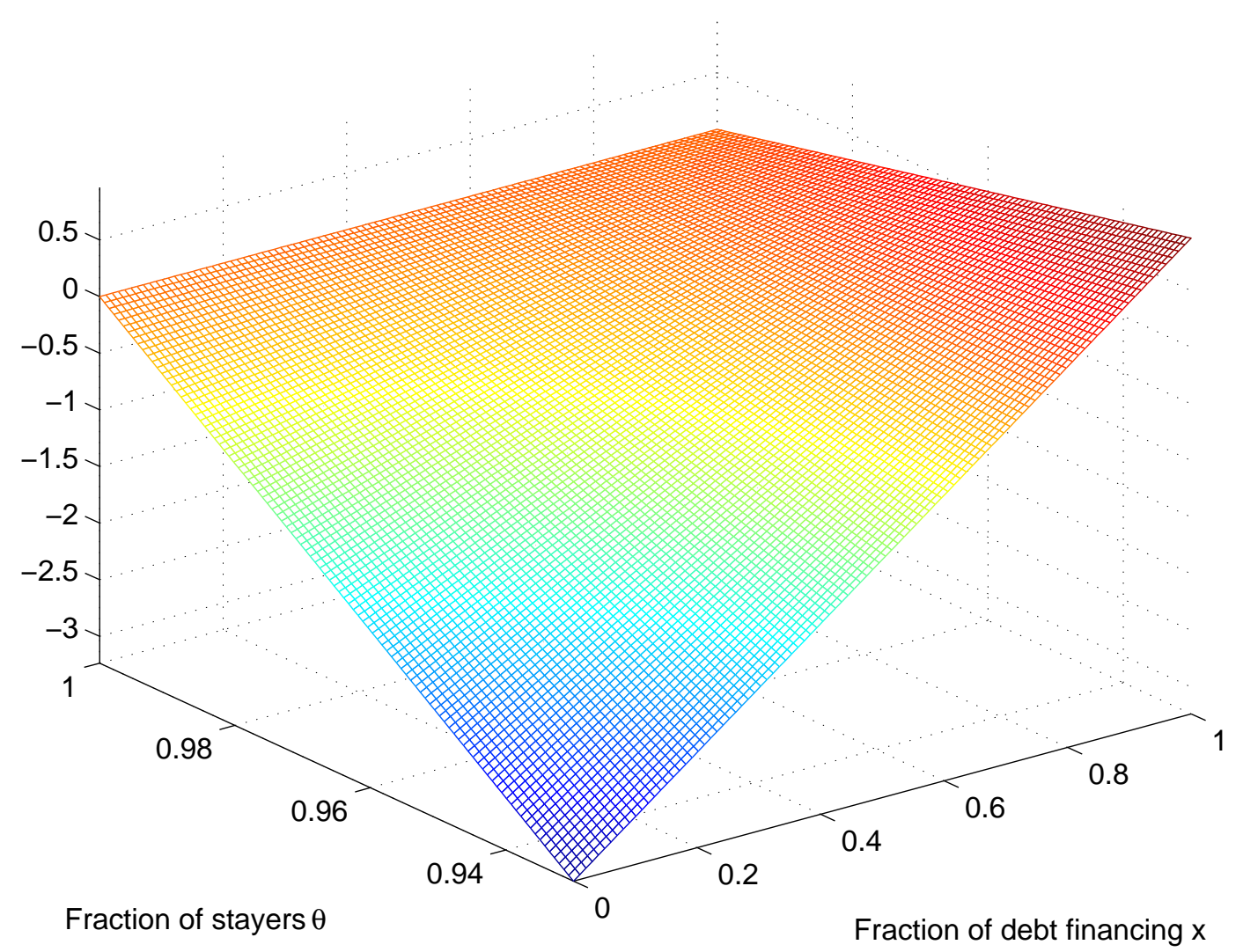

Figure 2: Logarithm of public good provision with no pop. growth and constant mobility rate, $\delta=0.06$. 


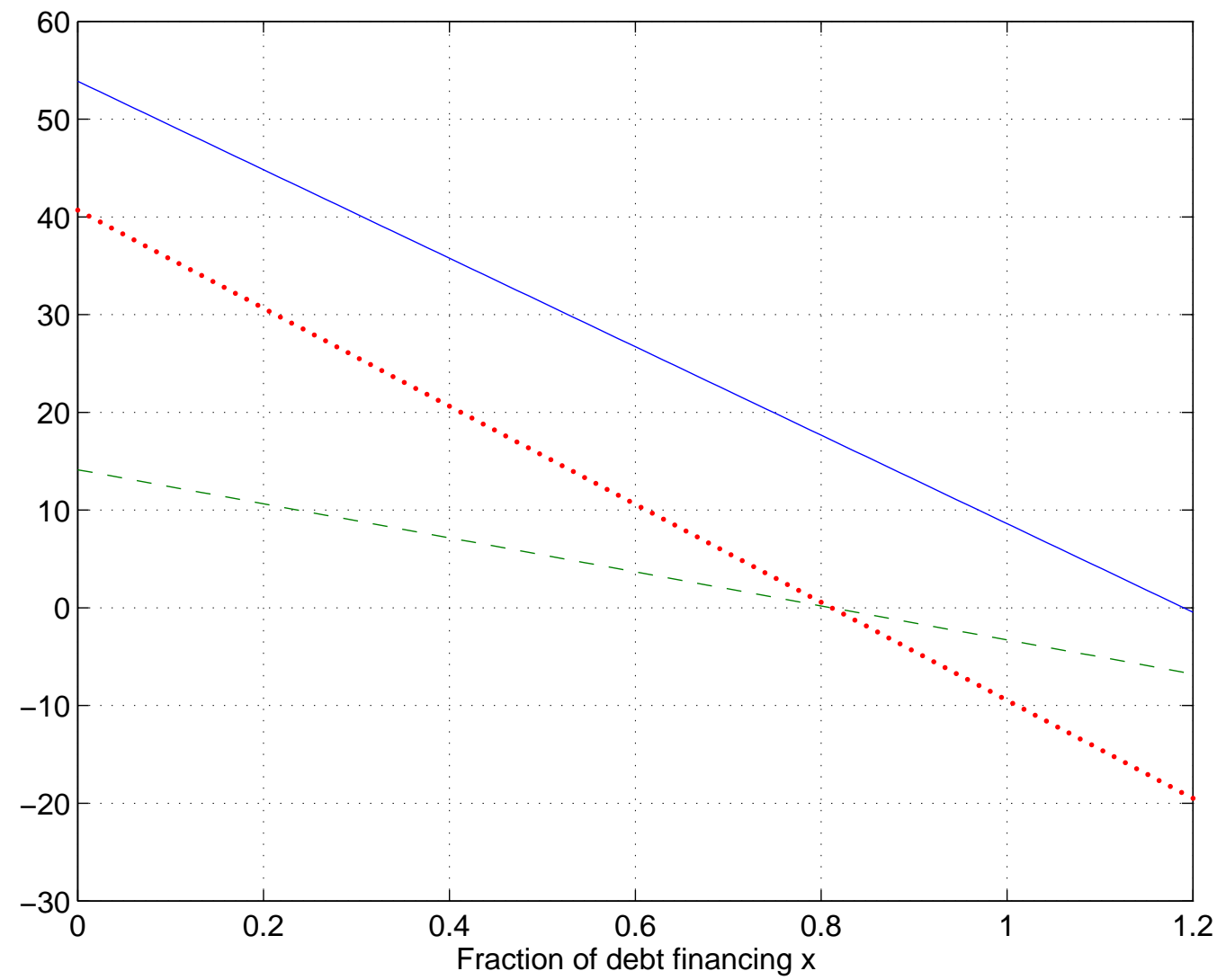

Figure 3: Coefficients $B_{n}$ (solid), $B_{\theta}$ (dashed), and $B_{\theta}^{*}$ (dotted). 


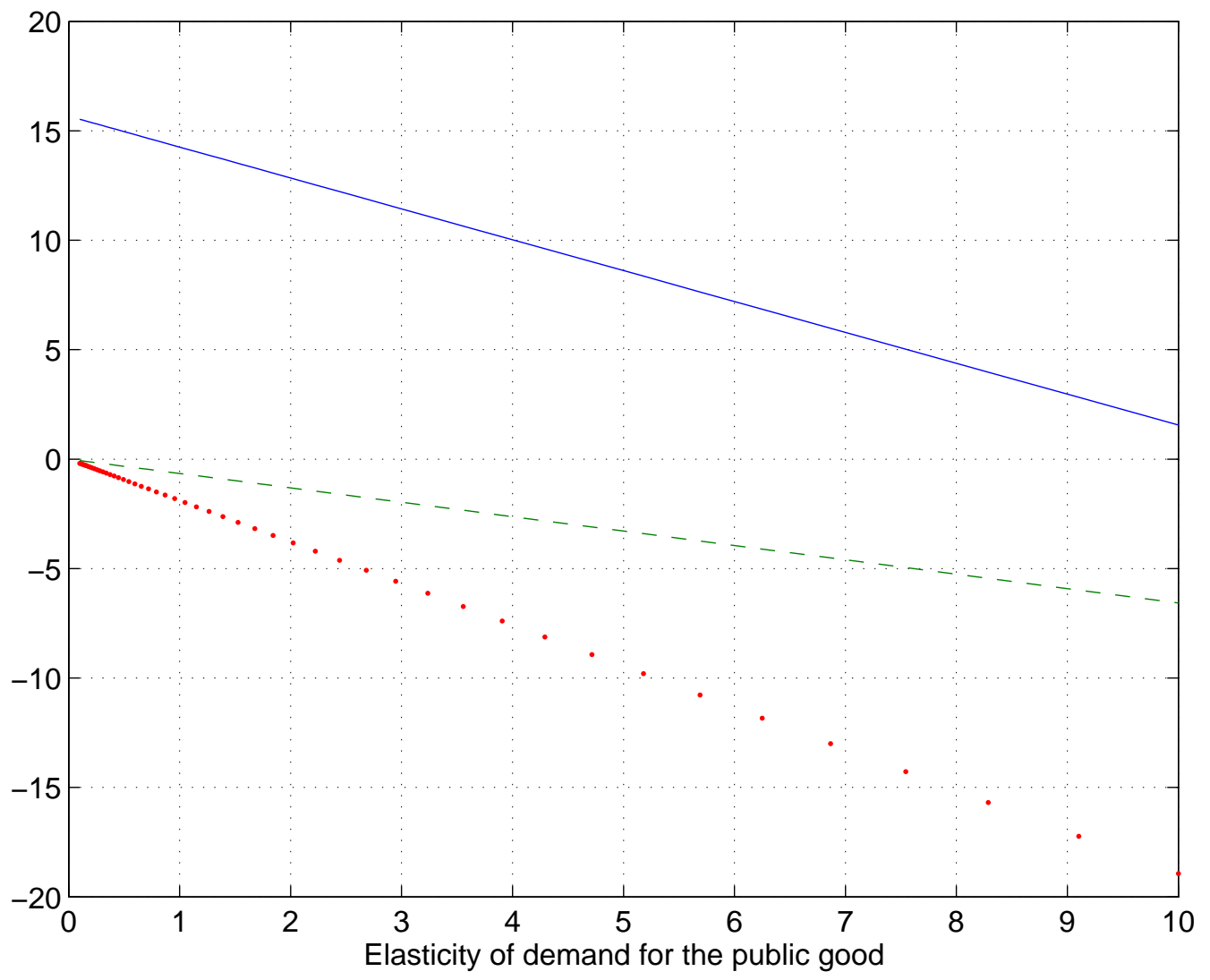

Figure 4: Coefficients $B_{n}$ (solid), $B_{\theta}$ (dashed), and $B_{\theta}^{*}$ (dotted). 


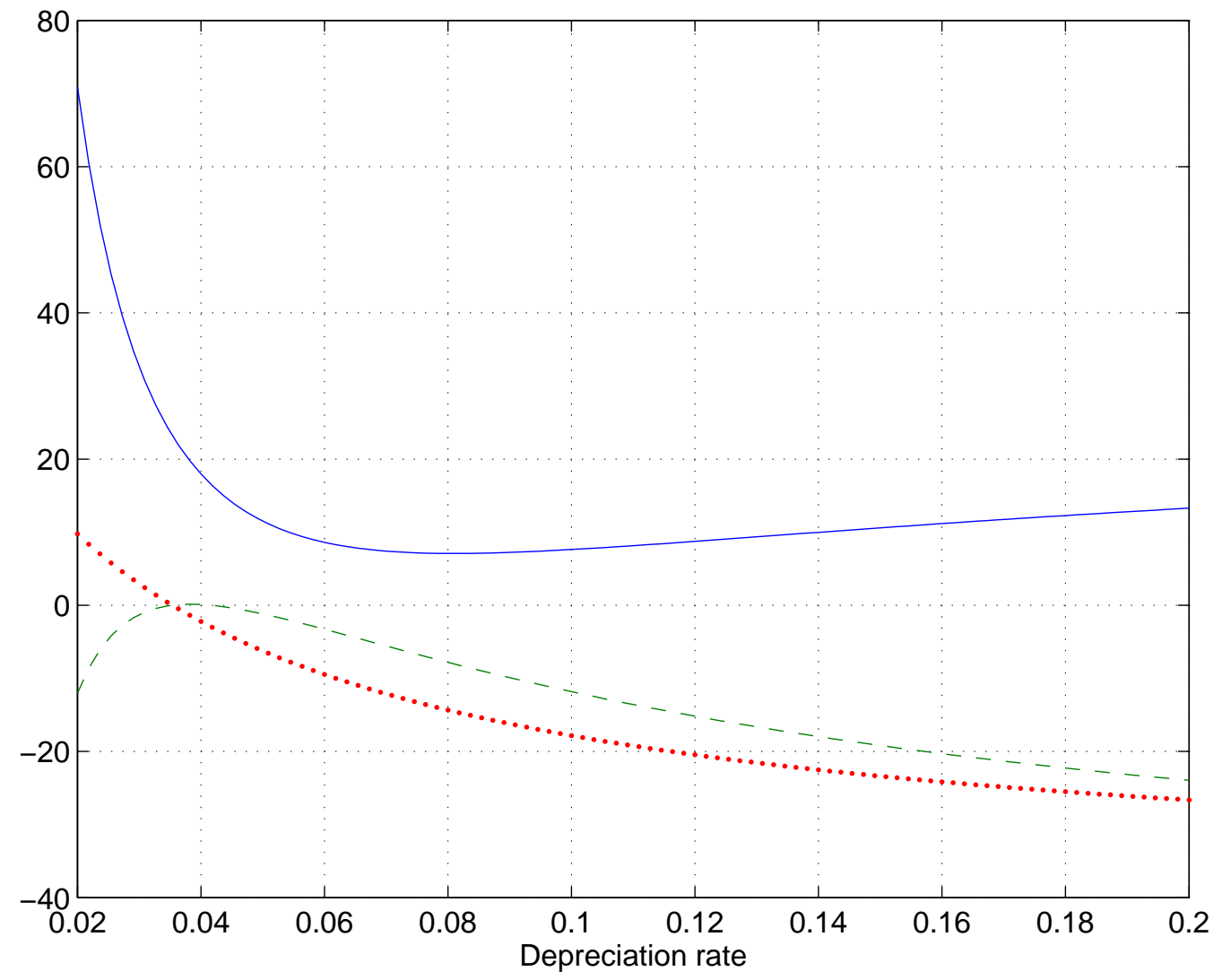

Figure 5: Coefficients $B_{n}$ (solid), $B_{\theta}$ (dashed), and $B_{\theta}^{*}$ (dotted). 


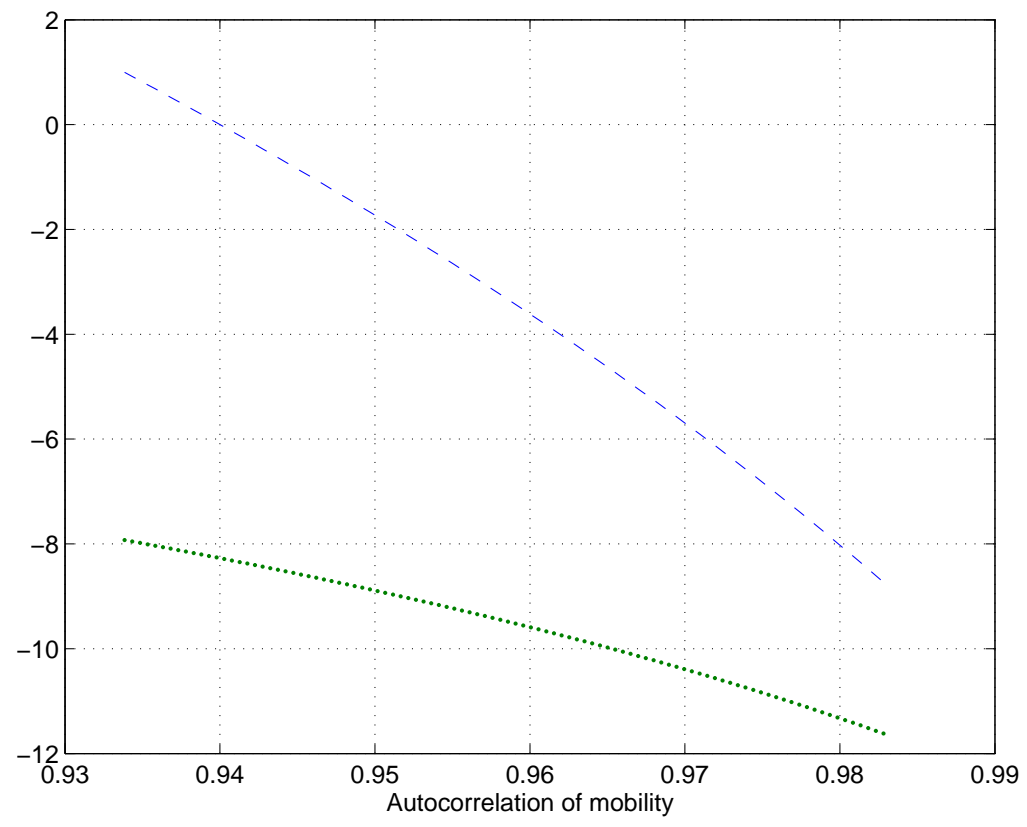

Figure 6: Coefficients $B_{\theta}$ (dashed), and $B_{\theta}^{*}$ (dotted). 


\section{A Efficient Allocations}

Since households have linear preferences in private consumption, we are in a transferable utility environment, and the Pareto frontier can be derived by maximizing the sum of the utilities of all the households. This maximization will uniquely determine aggregate private consumption, but not its distribution across people: the Pareto frontier is traced by varying this distribution.

Letting $C_{t}$ be average per capita consumption in period $t$ and $N_{s t}$ the number of residents of state $s$ in period $t$, a Pareto-efficient allocation solves:

$$
\max _{\left(C_{t}, G_{s t}, \gamma_{s t}\right)_{t=0}^{\infty}} E_{0}\left\{\sum_{t=0}^{\infty} \beta^{t} \sum_{s \in \text { U.S.A. }} N_{s t}\left[C_{t}+\phi_{s t} \frac{G_{s t}^{1-\sigma}}{1-\sigma}\right]\right\}
$$

subject to (2) for each state, and to the aggregate resource constraint

$$
\sum_{s \in \text { U.S.A. }} N_{s t}\left[y-C_{t}-\gamma_{s t}\right] \geq 0, \quad t \geq 0
$$

The expectation in (17) is taken with respect to the population count in each state (governed by the stochastic process for population growth) and the preference shock.

The first-order conditions for this problem yield

$$
\phi_{s t} G_{s t}^{-\sigma}=1-\beta(1-\delta) .
$$

\section{B Definition of an Equilibrium}

This definition is similar to the one in Bassetto with Sargent [7]. All the notation that is not explicitly defined here is the same as in our main text.

A tax-debt policy are bounded sequences $\left\{\left\{T_{s t}, B_{s t}\right\}_{s \in \text { U.S.A. }}\right\}_{t=0}^{\infty}$. A price system is a sequence $\left\{r_{t}\right\}_{t=0}^{\infty}$.

We consider the problem of a household that starts at time $t$, taking as given the price system and the tax policy from $t$ on: ${ }^{37}$

$$
\max _{\left\{\left(c_{j}, a_{j}\right)\right\}_{j=t}^{\infty}} E_{t}\left[\sum_{j=t}^{\infty} \beta^{j-t} c_{j}+\phi_{s_{j} j} \frac{G_{s_{j} j}^{1-\sigma}}{1-\sigma}\right]
$$

\footnotetext{
${ }^{37}$ As mentioned in the text, for simplicity we abstract from death, so the household has an infinite life span. Because of population growth, new households do enter into the economy every period.
} 
subject to the flow budget constraint

$$
c_{j}+a_{j}+T_{s_{j} j} \leq\left(1+r_{j}\right) a_{j-1}+y
$$

where $a_{j}$ are a households' assets at the end of period $j$, and $s_{j}$ is the state where the household resides in period $j$. In equation (19), the expectation is over two sources of uncertainty. First, an individual household is uncertain about $s_{j}$ (except for the initial period). We assume that location follows a Markov process, where the probability distribution over the state of residence next period only depends on the state of residence in the current period; this distribution is assumed to be common to all households. A full description of this uncertainty would require the entire $50 \times 50$ (time-varying) transition matrix. However, for the Markov equilibria that we will consider it is sufficient to keep track of the probability of leaving a given state $s$ conditional on residing there in period $j$, which is $1-\theta_{s j}$ and is assumed to follow a $\mathrm{AR}(1)$ process as described in the main text. The second source of uncertainty is the preference shock on the public good, $\phi_{s_{j} j}$. We assume that this shock is bounded and that it is common to all households residing in the same state. Since our empirical analysis clusters standard errors at the state level, no further assumption is needed on its distribution.

To prevent Ponzi schemes, a household must also face a lower bound on assets; we assume that $a_{j}$ is uniformly bounded from below. ${ }^{38}$

The household problem has a solution only if $r_{j}=(1-\beta) / \beta$. When this interest rate prevails, a household is indifferent about all consumption and asset profiles that meet its budget constraint; it is thus not necessary to keep track of individual consumption and saving decisions across time and for different realizations of the shocks, and households will be willing to absorb any amount of bonds supplied by the states. In this case, a household's welfare is

$$
\frac{a_{t-1}}{\beta}+\frac{y}{1-\beta}+\sum_{j=t}^{\infty} \beta^{j-t}\left[\phi_{s_{j} j} \frac{G_{s_{j} j}^{1-\sigma}}{1-\sigma}-T_{s_{j} j}\right]
$$

We define a competitive equilibrium from time $t$ as a real allocation $\left\{C_{j},\left\{\gamma_{s j}, G_{s j}\right\}_{s \in U . S . A .}\right\}_{j=t}^{\infty}$, a tax-debt policy $\left\{\left\{T_{s j}, B_{s j}\right\}_{s \in \text { U.S.A. }}\right\}_{j=t}^{\infty}$, a price system $\left\{r_{j}\right\}_{j=t}^{\infty}$, and initial conditions $\left\{B_{s t-1}\right\}_{s \in \text { U.S.A. }}$, such that:

\footnotetext{
${ }^{38} a_{j}$ is a random variable adapted to the history of the households' residence states and to the aggregate shocks.
} 
(i) $r_{j}=(1-\beta) / \beta \forall j \geq t$, ensuring that the households' problem has a solution;

(ii) at any time $j$, the allocation satisfies the feasibility conditions (2) and (18);

(iii) the state government budget constraints and debt limits (3) and (4) hold for all states and in every period.

Next we define a political-economic equilibrium in which residents of a state collectively choose public spending and investment each period. To evaluate those choices, households must form expectations about the evolution of the economy. A history of the economy is a sequence $h^{t} \equiv\left\{\left\{\left(G_{s, j-1}, \phi_{s j}, \theta_{s j}, n_{s j}\right)\right\}_{s \in \text { U.S.A. }}\right\}_{j=0}^{t}$, for any $t \geq 0$, where $\left\{G_{s-1}\right\}_{s \in \text { U.S.A. }}$ is an exogenous initial condition. ${ }^{39}$ We define a political-economic equilibrium in terms of a mapping $\Psi$ defined as follows:

- To each history $h^{t}, \Psi$ associated a time- $t$ provision of public capital $\left\{G_{s t}\left(h^{t}\right)\right\}_{s \in \text { U.S.A.; }}$;

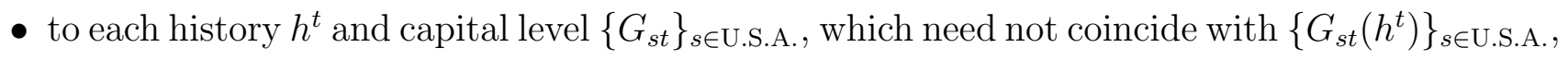
the mapping $\Psi$ associates an allocation $\left(C\left(h^{t},\left\{G_{s t}\right\}_{s \in \text { U.S.A. }}\right),\left\{\gamma_{s}\left(h^{t},\left\{G_{s t}\right\}_{s \in \text { U.S.A. }}\right)\right\}_{s \in \text { U.S.A. }}\right)$, and a time- $t$ tax-debt policy $\left(\left\{B_{s}\left(h^{t},\left\{G_{s t}\right\}_{s \in \text { U.S.A. }}\right), T_{s}\left(h^{t},\left\{G_{s t}\right\}_{s \in \text { U.S.A. }}\right)\right\}_{s \in \text { U.S.A. }}\right)$.

Given any history $h^{j}$, each mapping $\Psi$ recursively generates a history from $h^{j}$, along with the exogenous evolution of the shocks:

$$
h^{t} \equiv\left(h^{t-1},\left\{\left(G_{s t-1}\left(h^{t-1}\right), \phi_{s t}, \theta_{s t}, n_{s t}\right)\right\}_{s \in \text { U.S.A. }}\right) .
$$

From any initial condition $h^{j}, j \geq 0$, the sequence of histories recursively generated as above induce an allocation and a tax/debt policy from the initial conditions $\left\{\left(G_{s j-1}, \phi_{s j}, \theta_{s j}, n_{s j}\right)\right\}_{s \in \text { U.S.A. }}$, which are part of $h^{j}$, and $\left\{B_{s}\left(h^{j-1},\left\{G_{s j-1}\right\}_{s \in \text { U.S.A. }}\right)\right\}_{s \in \text { U.S.A. }}{ }^{40}$

A mapping $\tilde{\Psi} \equiv(\{\tilde{G}, \tilde{C}, \tilde{\gamma}, \tilde{B}, \tilde{T})$ is a political-economic equilibrium when it has the following properties.

\footnotetext{
${ }^{39}$ Although other variables could be introduced as part of the history, it can be shown that their presence would be redundant with the definition of an equilibrium below.

${ }^{40} h^{j-1}$ is the predecessor of the history $h^{j}$. When we consider an initial history $h^{0},\left\{B_{s}\left(h^{-1}\right)\right\}_{s \in \text { U.S.A. is an }}$ initial level that is exogenously given.
} 
(i) (Competitive equilibrium) Given any history $h^{j}$, including the null history, the real allocations and the tax/debt policy induced by $\tilde{\Psi}$ form a competitive equilibrium, together with the constant interest rate $(1-\beta) / \beta$.

(ii) (Self-interested voting) Given any history $h^{j}, j \geq 0, \tilde{G}_{s}\left(h^{j-1}\right)$ is the policy preferred by residents of the state $s$ at time $j$, assuming that in the future the economy will follow the path implied by $\tilde{\Psi}$, and taking as given the contemporaneous political choice of residents of other states. Using (21), this requires that the following inequality holds for all values of $G$ and all states $S$ :

$$
\begin{aligned}
& \phi_{S j} \frac{G^{1-\sigma}}{1-\sigma}-\tilde{T}_{S j}\left(h^{j},\left\{\hat{G}_{s}\left(h^{j}\right)\right\}_{s \in \text { U.S.A. }}\right)+ \\
& E_{j} \sum_{t=1}^{\infty} \phi_{s_{j+t} j+t} \frac{\tilde{G}_{s_{j+t}}\left(\hat{h}^{j+t}\right)^{1-\sigma}}{1-\sigma}-\tilde{T}_{s_{j+t}}\left(\hat{h}^{j+t},\left\{\tilde{G}_{s}\left(\hat{h}^{j+t}\right)\right\}_{s \in \text { U.S.A. }}\right) \leq \\
& \phi_{S j} \frac{\tilde{G}_{S}\left(h^{j}\right)^{1-\sigma}}{1-\sigma}-\tilde{T}_{S j}\left(h^{j},\left\{\tilde{G}_{s}\left(h^{j}\right)\right\}_{s \in \text { U.S.A. }}\right)+ \\
& E_{s} \sum_{t=1}^{\infty} \phi_{s_{j+t} j+t} \frac{\tilde{G}_{s_{j+t}}\left(\tilde{h}^{j+t}\right)^{1-\sigma}}{1-\sigma}-\tilde{T}_{s_{j+t}}\left(\tilde{h}^{j+t},\left\{\tilde{G}_{s}\left(\hat{h}^{j+t}\right)\right\}_{s \in \text { U.S.A. }}\right),
\end{aligned}
$$

where the following definitions hold:

- $\hat{G}_{s}\left(h^{j}\right)=\tilde{G}_{s}\left(h^{j}\right) \quad \forall s \neq S, \quad \hat{G}_{S}\left(h^{j}\right)=G$. In words, this is the public good provision in period $j$ when state $S$ deviates.

$$
\begin{gathered}
\hat{h}^{j+1}=\left(h^{j},\left\{\left(\hat{G}_{s}\left(h^{j}\right), \phi_{s j+1}, \theta_{s j+1}, n_{s j+1}\right)\right\}_{s \in \text { U.S.A. }}\right), \\
\hat{h}^{j+t}=\left(h^{j+t-1},\left\{\left(\tilde{G}_{s}\left(\hat{h}^{j+t-1}\right), \phi_{s j+t}, \theta_{s j+t}, n_{s j+t}\right)\right\}_{s \in \text { U.S.A. }}\right), \quad t>1:
\end{gathered}
$$

these are the histories induced by $\Psi$ after a deviation by state $S$ at history $h^{j}$.

$$
\begin{gathered}
\tilde{h}^{j+1}=\left(h^{j},\left\{\left(\tilde{G}_{s}\left(h^{j}\right), \phi_{s j+1}, \theta_{s j+1}, n_{s j+1}\right)\right\}_{s \in \text { U.S.A. }}\right), \\
\tilde{h}^{j+t}=\left(h^{j+t-1},\left\{\left(\tilde{G}_{s}\left(h^{j+t-1}\right), \phi_{s j+t}, \theta_{s j+t}, n_{s j+t}\right)\right\}_{s \in \text { U.S.A. }}\right), \quad t>1:
\end{gathered}
$$

these are the histories induced by $\Psi$ if no deviations occur. 
In equation $(22), s_{j+t}$ is a random variable that is determined by the exogenous stochastic process for mobility, conditional on $s_{j}=S$. Notice that all residents of the state face the same mobility process, and hence they share the same preferences over public good provision.

(iii) (Budget balance) Given any history $h^{j}$, any realization of shocks and political decisions, and any state $S$, taxes are set as follows:

$$
\tilde{T}_{S}\left(h^{j},\left\{G_{s j}\right\}_{s \in \text { U.S.A. }}\right)=\frac{\alpha+\frac{1-\beta}{\beta}}{1+n_{s j}} \tilde{B}_{S}\left(h^{j-1},\left\{G_{s j-1}\right\}_{s \in \text { U.S.A. }}\right)+(1-x)\left[G_{S j}-(1-\delta) G_{S j-1}\right],
$$

where $G_{s j-1}$ is the appropriate element of the history $h^{j}$.

Requirement (i) states that no matter what happened in the past, $\tilde{\Psi}$ prescribes a path that is a competitive equilibrium. Requirement (ii) states that at each time $j$, residents of each state prefer not to deviate from the equilibrium path prescribed by $\tilde{\Psi}$, taking into account how a deviation effects contemporaneous utility and also how it affects the future by altering subsequent histories. Requirement (iii) embodies the limit on the ability to borrow to pay for public spending, and the repayment schedule on existing debt.

The definition above allows for arbitrary dependence on histories, including equilibria in which a deviation by a state triggers responses in other states.

We focus on Markov equilibria, in which public good provision $G_{s t}$ is independent of the past and also of the choices and shocks of all other states; $G_{s t}$ is only affected by the contemporaneous realizations $\phi_{s t}, \theta_{s t}, n_{s t}$.

Proposition 1 A Markov equilibrium (defined above) exists and is unique.

Proof. The proof is by construction. In the main text, we showed that, if the future provision of public goods only depends on future realizations of the shocks, then residents will choose $G_{s t}$ according to equation (6). This choice is unique, and it only depends on the contemporaneous shocks, verifying the Markov nature of the equilibrium. 


\section{Derivation of Equation (9)}

Suppose that investment is decided $k$ years ahead of time. Let $G_{s t}^{\mathrm{TOT}}$ be the total stock of public capital in state $s$ and period $t$ (i.e., $G_{s t}^{\mathrm{TOT}} \equiv G_{s t} N_{s t}$, where $N_{s t}$ is the population in state $s$ at time $t$. We conjecture (and verify) an equilibrium in which $G_{s t}^{\mathrm{TOT}}$ is independent of the past.

To solve for the equilibrium, it is useful to rewrite (2), (3), and (4) in total terms, rather than as per capita quantities: ${ }^{41}$

$$
\begin{gathered}
G_{s t}^{\mathrm{TOT}}=(1-\delta) G_{s t-1}^{\mathrm{TOT}}+\gamma_{s t}^{\mathrm{TOT}} \\
B_{s t}^{\mathrm{TOT}}=(1+r) B_{s t-1}^{\mathrm{TOT}}+\gamma_{s t}^{\mathrm{TOT}}-T_{s t}^{\mathrm{TOT}},
\end{gathered}
$$

and

$$
T_{s t}^{\mathrm{TOT}} \geq(1-x) \gamma_{s t}^{\mathrm{TOT}}+(\alpha+r) B_{s t-1}^{\mathrm{TOT}}
$$

Using the equations above, we can derive the consequences that the voters expect from a marginal increase in $G_{s t}^{\mathrm{TOT}}$ enacted by a vote in period $t-k$ :

- Marginal benefit of investment in period $t$ :

$$
\phi_{s t}\left(G_{s t}^{\mathrm{TOT}}\right)^{-\sigma}\left(N_{s t}\right)^{\sigma-1}
$$

- Increase in total taxes in period $t: 1-x$;

- Decrease in total investment in period $t+1: 1-\delta$ (due to the conjecture about the nature of the equilibrium);

- Change in total taxes in period $t+1$ :

$$
(\alpha+r) x-(1-\delta)(1-x)
$$

- Change in total taxes in subsequent periods $t+j, j>1$ :

$$
(\alpha+r)(1-\alpha)^{j-2}(\delta-\alpha) x .
$$

\footnotetext{
${ }^{41}$ Since we already know that the interest rate is constant, we dropped its time subscript here.
} 
These costs and benefits are exactly the same, independently of the planning horizon; what changes is the information available to voters when they compute their expected value.

It is straightforward to see that the probability of moving between $t-k$ and $t$ is irrelevant from the voters' perspective: the outcome of the vote will only affect them if they are still in state at time $t$, so their vote will maximize utility conditional on this realization. Their first-order condition will thus be:

$\left(G_{s t}^{\mathrm{TOT}}\right)^{-\sigma} E_{t-k}\left[\phi_{s t}\left(N_{s t}\right)^{\sigma-1}\right]=$
$E_{t-k}\left[\frac{1-x}{N_{s t}}+\frac{\beta \theta_{s t+1}}{N_{s t+1}}[x(\alpha+r)-(1-x)(1-\delta)]+x(\alpha+r)(\delta-\alpha) \sum_{j=2}^{\infty} \frac{\beta^{j}(1-\alpha)^{j-2} \prod_{v=1}^{j} \theta_{s t+v}}{N_{s t+j}}\right]$.

Equation (27) takes into account that an individual will pay taxes on a per capita basis.

As in the main text, we linearize this expression around $n_{s t}=0$ and $\theta_{s t}=1$, and assume an $\operatorname{AR}(1)$ process for $n_{s t}$ and $\theta_{s t+k}$.

We thus obtain

$$
\begin{aligned}
& E_{t-k} \log G_{s t} \approx \frac{1}{\sigma}\left[E_{t-k} \log \phi_{s t}-\log (1-\beta(1-\delta))-\right. \\
& \frac{\beta(1-\delta)}{1-\beta(1-\delta)}\left(1+\bar{n}-\bar{\theta}-\rho_{\theta}^{k+1}\left(\theta_{s t-k}-\bar{\theta}\right)+\rho_{n}^{k+1}\left(n_{s t-k}-\bar{n}\right)\right)+ \\
& x\left[\frac{1+\bar{n}-\bar{\theta}}{1-\beta(1-\alpha)}+\frac{\rho_{n}^{k+1}\left(n_{s t-k}-\bar{n}\right)\left(1-\beta \rho_{n}(1-\delta)\right)}{(1-\beta(1-\delta))\left(1-\beta \rho_{n}(1-\alpha)\right)}-\frac{\rho_{\theta}^{k+1}\left(\theta_{s t-k}-\bar{\theta}\right)\left(1-\beta \rho_{\theta}(1-\delta)\right)}{(1-\beta(1-\delta))\left(1-\beta \rho_{\theta}(1-\alpha)\right)}\right] .
\end{aligned}
$$

In equation (28), note that the $\log G_{s t}$ is uncertain as of time $t-k$ because of population growth, even though $G_{s t}^{\mathrm{TOT}}$ is known:

$$
\begin{aligned}
\log G_{s t} & \approx E_{t-k} \log G_{s t}-\left[\sum_{j=1}^{k} n_{s t+j-k}-E_{t-k} \sum_{j=1}^{k} n_{s t+j-k}\right]= \\
E_{t-k} \log G_{s t}- & {\left[\sum_{j=1}^{k} n_{s t+j-k}-k \bar{n}-\frac{\rho_{n}\left(1-\rho_{n}^{k}\right)}{1-\rho_{n}}\left(n_{s t-k}-\bar{n}\right)\right] . }
\end{aligned}
$$

Next, linearizing the investment equation we obtain

$$
\log \gamma_{s t} \approx \log \delta+\frac{1}{\delta}\left(\log G_{s t}-(1-\delta) \log G_{s t-1}\right)+\frac{1-\delta}{\delta} n_{s t} .
$$

Combining (28), (29), and (30), we obtain (9). 


\section{Robustness Experiments}

The tables that follow show how our results survive to a number of robustness checks.

- Table 8 uses a different measure of stayers, based on Census data. When we use the Census Migration measure, we are able to expand our sample to the years 1959-2007 for the contiguous states and to 1963-2007 for Alaska and Hawaii. ${ }^{42}$ The Census asked for information on current state of residence and state of residence five years prior. We define movers for a given year as one-fifth of the fraction of the population living in a state five years prior to the Census and living in a different state in the Census year. We interpolate between the years five years prior to consecutive Censuses. For the years following 1995 (data for 1995 is measured in the 2000 Census), we forecast migration based on state fixed effects, state specific time trends, and demographic variables (educational attainment, homeownership, urbanization, population, income, poverty rates, and population age structure). The correlation between the IRS and Census Mobility measures is .95 through 1995 and .85 after 1995. This regression confirms our key facts: a weak relationship between population growth and spending for all variables except for purchases of land and existing structures, and a significant negative relationship between the fraction of stayers and spending (again, except for land).

- We repeat our exercise excluding Alaska and Hawaii (Table 9). While Hawaii is not particularly different from other states, Alaska is a large outlier owing to its particular economy and geography. Our finding on the relationship between mobility, population growth, and capital spending are robust to restricting the sample to the contiguous 48 states. The relationship between the fraction of stayers and spending remains negative and significant, albeit somewhat smaller and actually closer to the values predicted by the theoretical model.

- Not all states split responsibilities in the same way between the state and local governments.

\footnotetext{
${ }^{42}$ The Alaska and Hawaii data is limited due to the absence of political variables as well as information on educational attainment in the years leading up to and including 1959, when these states joined the union.
} 
To check that our results are not driven by systematic variation in this split, Table 10 repeats our exercise combining state and local spending. ${ }^{43}$ We do not have separate data on purchases of land and structures and equipment at the local level, so we are forced to lump the two. When we combine state and local expenditures, capital spending is more responsive to population growth, closer to what our theoretical model would predict. The coefficient on the fraction of stayers drops, but it remains negative and significant (except for the combined land/equipment category); this coefficient too gets closer to the model predictions. One other change worth of note is that mobility within the state (INTMIG) ceases to be a significant predictor of spending.

- Table 11 includes net domestic migration and its lags as a separate regressor. ${ }^{44}$ In our model, net migration plays no independent role. However, Rappaport [20] proposes a theory where government spending drives net migration, and in this case our results could be affected by reverse causation. As we can see from the table, the inclusion of net migration has very little effect on our estimates for the coefficients on the fraction of stayers. This is not surprising, because net and gross migration are very weakly correlated: in our sample, the correlation between stayers and net migration is -0.18 . Net migration is more closely linked to population growth. Including net migration does have some effect on the coefficients for population growth, but the changes show no systematic pattern and do not alter our main conclusions. In line with Rappaport's findings at the local level, net migration itself is negatively related to current spending, while no clear relationship emerges for capital spending.

- Besley, Persson, and Sturm [11] argue that political competition is an important determinant of the mix of state spending. To check that our results are not driven by correlation with this omitted variable, we include the measure (labeled POLCOMP) as an additional

\footnotetext{
${ }^{43}$ The Census Bureau did not report data on local spending for 2001 and 2003, so we dropped those two years from the sample.

${ }^{44}$ Our variable is defined as the ratio of net new comers in a given year from the IRS data to the total population of the state in the previous year.
} 
control in Table 12. Data limitations restrict our sample to $1980-2004 .{ }^{45}$ Our conclusions are largely unaffected. The main change is a reduction (in absolute value) in the coefficients of stayers on non-highway total spending and construction, to values closer to what our theoretical model would predict; the coefficient on purchases of land and existing structures increases, but remains imprecisely estimated. These changes are due to the different sample period; POLCOMP has very little effect on our coefficients of interest. Our regression indirectly confirms Besley, Persson, and Sturm's findings about POLCOMP: our point estimates indicate that more political competition has a bigger (negative) proportional effect on current spending than on capital spending, thus raising the share of spending devoted to capital. However, these estimates are not statistically significant given our different controls and identification strategy.

- Finally, we check whether our results survive if we restrict ourselves to within-state variation by including state fixed effects; this is done in Table 13. Our coefficients on stayers are remarkably robust to this big change in our identification strategy. In contrast, within a state, population growth seems to have a more positive effect on capital spending than across states, with coefficients closer to what would be predicted by the theoretical model.

\footnotetext{
${ }^{45}$ We have POLCOMP up to 2001; since all of our controls are lagged 3 years, in accordance with the procedure for dealing with implementation lags, this implies that 2004 is the last year of usable data for our spending variables.
} 


\begin{tabular}{|c|c|c|c|c|c|c|c|}
\hline & (1) & (2) & (3) & (4) & (5) & (6) & $(7)$ \\
\hline VARIABLES & TOTCAP & NHCAP & LAND & EQUIP & CONSTR & NHCONSTR & CURREN] \\
\hline $\mathrm{POPGR}_{t}$ & -0.0413 & 0.771 & 3.866 & 1.532 & -0.568 & 0.318 & -0.180 \\
\hline & $(1.074)$ & (1.367) & (2.690) & (1.345) & (1.081) & (1.500) & $(0.826)$ \\
\hline POPGR $_{t-1}$ & $1.348^{* * *}$ & $2.321^{* *}$ & -0.862 & $2.634^{* *}$ & $1.231^{* *}$ & $2.272^{* *}$ & -0.0910 \\
\hline & $(0.433)$ & $(0.886)$ & $(2.281)$ & (1.037) & $(0.507)$ & $(0.927)$ & $(0.428)$ \\
\hline $\mathrm{POPGR}_{t-2}$ & 0.109 & -0.0697 & $3.758^{*}$ & -0.420 & -0.0975 & -0.825 & $-0.741^{*}$ \\
\hline & $(0.590)$ & (1.037) & (2.106) & $(0.928)$ & $(0.659)$ & (1.043) & $(0.379)$ \\
\hline $\mathrm{POPGR}_{t-3}$ & 0.898 & $2.208^{*}$ & 2.331 & -0.244 & 0.784 & 2.084 & 0.0795 \\
\hline & $(0.591)$ & $(1.273)$ & (2.141) & (1.001) & $(0.624)$ & (1.371) & (0.493) \\
\hline POPGR $_{t-4}$ & -1.463 & -2.175 & $5.207^{* *}$ & $-2.116^{*}$ & $-2.013^{*}$ & -1.973 & -0.282 \\
\hline & (1.039) & (1.473) & $(2.278)$ & $(1.230)$ & (1.113) & (1.945) & $(0.754)$ \\
\hline $\mathrm{STAY}_{t}$ & -37.72 & -6.834 & 8.092 & -12.05 & -40.28 & -20.28 & 5.391 \\
\hline & $(24.40)$ & $(30.36)$ & $(54.71)$ & (18.18) & (26.03) & $(35.25)$ & $(17.84)$ \\
\hline $\mathrm{STAY}_{t-1}$ & 5.198 & -4.869 & -56.25 & 6.525 & 3.195 & -1.136 & -0.986 \\
\hline & $(9.512)$ & (16.02) & (40.49) & (12.33) & (10.48) & (22.13) & $(4.881)$ \\
\hline $\operatorname{STAY}_{t-2}$ & -1.753 & 0.844 & -0.660 & $24.83^{*}$ & -3.591 & 0.592 & 4.312 \\
\hline & (9.640) & (16.34) & $(52.46)$ & $(14.26)$ & (10.61) & (20.47) & $(4.705)$ \\
\hline $\mathrm{STAY}_{t-3}$ & $33.94^{* *}$ & $38.29^{*}$ & 96.12 & 16.53 & $30.69^{* *}$ & $50.33^{*}$ & $17.18^{* *}$ \\
\hline & $(13.23)$ & $(22.84)$ & (65.11) & $(15.73)$ & (13.93) & (29.58) & $(6.446)$ \\
\hline $\operatorname{STAY}_{t-4}$ & -28.53 & -38.66 & -49.73 & $-46.81^{* * *}$ & -21.45 & -45.04 & $-37.21^{* *}$ \\
\hline & (20.19) & (27.69) & $(51.25)$ & $(17.26)$ & (21.38) & (36.43) & (18.15) \\
\hline Sums & & & & & & & \\
\hline POPGR, undiscounted: & 0.851 & 3.06 & $14.3^{* *}$ & 1.38 & -0.664 & 1.88 & -1.21 \\
\hline & $(2.55)$ & $(3.51)$ & (6.63) & $(2.60)$ & $(2.69)$ & $(3.74)$ & $(2.14)$ \\
\hline POPGR, discounted $\left(B_{n}\right)$ : & 0.488 & 2.92 & $20.1^{* *}$ & 0.0248 & -1.55 & 1.58 & -1.61 \\
\hline & $(3.50)$ & $(5.03)$ & $(9.10)$ & $(3.52)$ & $(3.72)$ & $(5.37)$ & $(2.88)$ \\
\hline STAY, undiscounted $\left(B_{\theta}^{*}\right)$ : & $-28.9^{* * *}$ & $-11.2^{* *}$ & -2.43 & $-11.0^{* *}$ & $-31.4^{* * *}$ & $-15.5^{* *}$ & $-11.3^{* * *}$ \\
\hline & $(5.35)$ & $(5.71)$ & $(12.7)$ & $(5.56)$ & $(5.95)$ & $(7.19)$ & $(2.91)$ \\
\hline STAY, discounted $\left(B_{\theta}\right)$ : & $-29.5^{* * *}$ & $-13.3^{*}$ & -1.10 & $-14.8^{* * *}$ & $-31.4^{* * *}$ & $-17.0^{* *}$ & $-15.4^{* * *}$ \\
\hline & $(5.24)$ & $(7.31)$ & (13.6) & $(5.19)$ & $(5.72)$ & $(8.60)$ & $(3.64)$ \\
\hline
\end{tabular}

Table 8: Continued on the next page 


$\begin{array}{lccccccc} & (1) & (2) & (3) & (4) & (5) & (6) & (7) \\ \text { VARIABLES } & \text { TOTCAP } & \text { NHCAP } & \text { LAND } & \text { EQUIP } & \text { CONSTR } & \text { NHCONSTR } & \text { CURRENT } \\ & & & & & & & \\ \text { INTMIG } & -1.775^{*} & -3.681^{* *} & -0.531 & -0.928 & -1.704^{*} & -3.974^{* *} & -2.841^{* * *} \\ & (0.888) & (1.376) & (1.760) & (1.284) & (0.887) & (1.502) & (0.716) \\ \text { STATEINC } & 0.0283^{* *} & 0.0490^{* * *} & 0.0229 & 0.0425^{* * *} & 0.0299^{* *} & 0.0628^{* * *} & 0.0221^{* *} \\ & (0.0122) & (0.0151) & (0.0224) & (0.0142) & (0.0128) & (0.0164) & (0.0106) \\ \text { EDU } & -0.277 & 0.227 & 0.111 & -0.348 & -0.377 & -0.147 & 1.252^{* * *} \\ & (0.513) & (0.655) & (1.115) & (0.583) & (0.548) & (0.783) & (0.390) \\ \text { URBAN } & -0.394 & -0.135 & 0.0740 & -0.275 & -0.429 & -0.171 & -0.585^{* *} \\ & (0.269) & (0.395) & (0.542) & (0.298) & (0.289) & (0.460) & (0.250) \\ \text { DENSITY } & -0.193 & -0.240 & 0.394 & -0.444 & -0.195 & -0.202 & -0.159 \\ & (0.156) & (0.345) & (0.530) & (0.289) & (0.148) & (0.410) & (0.241) \\ \text { OVER65 } & 0.0853 & -4.411^{*} & -3.524 & 1.384 & 0.221 & -5.436^{*} & -3.175^{*} \\ & (1.975) & (2.598) & (5.339) & (2.380) & (2.062) & (3.138) & (1.825) \\ \text { UNDER25 } & 2.256 & 3.589^{*} & -1.409 & 5.903^{* * *} & 2.356 & 3.606 & 1.085 \\ & (1.598) & (1.811) & (2.518) & (1.711) & (1.709) & (2.173) & (1.165) \\ \text { HOMEOWN } & -0.571 & -2.511^{* * *} & 0.133 & -0.0143 & -0.692 & -2.487^{* * *} & -0.675 \\ & (0.509) & (0.799) & (1.277) & (0.733) & (0.508) & (0.861) & (0.508) \\ \text { LIB } & 0.00436 & 0.0333 & -0.00966 & 0.00473 & 0.00220 & 0.0366 & 0.0674^{* * *} \\ & (0.0297) & (0.0367) & (0.0579) & (0.0326) & (0.0316) & (0.0414) & (0.0216) \\ \text { SIZE } & -1.986 & -3.179 & -0.783 & -5.214^{* * *} & -2.345 & -2.915 & -1.207 \\ & (1.366) & (1.986) & (4.028) & (1.873) & (1.461) & (2.180) & (1.836) \\ \text { Year Dummies } & \text { Yes } & \text { Yes } & \text { Yes } & \text { Yes } & \text { Yes } & \text { Yes } & \text { Yes } \\ \text { Observations } & 2,442 & 2,442 & 2,440 & 2,442 & 2,442 & 2,442 & 2,442 \\ \text { R-squared } & 0.622 & 0.601 & 0.218 & 0.717 & 0.605 & 0.612 & 0.723\end{array}$

Table 8: Robustness to measure of stayers and to length of sample: the fraction of stayers is here based on Census data. Regression of spending on population growth and the fraction of stayers and their lags, including controls. Year dummies are included, and standard errors are clustered at the state level. Significance is indicated at the $1 \%\left({ }^{* * *}\right), 5 \%(* *)$, and $10 \%\left({ }^{*}\right)$ levels. 


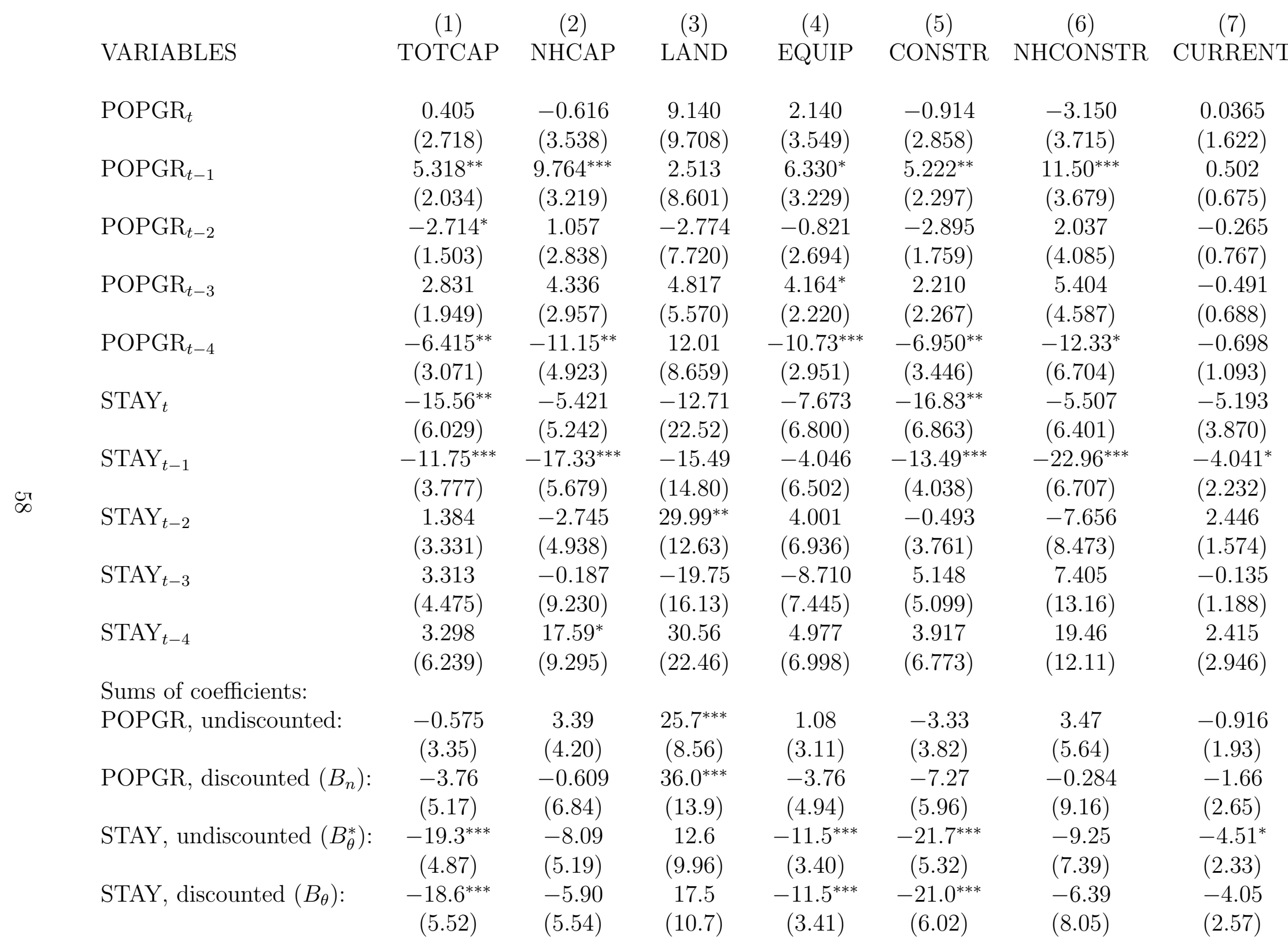

Table 9: Continued on the next page 


$\begin{array}{lccccccc} & (1) & (2) & (3) & (4) & (5) & (6) & (7) \\ \text { VARIABLES } & \text { TOTCAP } & \text { NHCAP } & \text { LAND } & \text { EQUIP } & \text { CONSTR } & \text { NHCONSTR } & \text { CURRENT } \\ & & & & & & & \\ \text { INTMIG } & -1.511 & -2.705 & 1.213 & -2.433 & -1.192 & -2.769 & -3.008^{* * *} \\ & (1.450) & (2.038) & (3.289) & (2.127) & (1.396) & (2.028) & (0.749) \\ \text { STATEINC } & 0.0165 & 0.0121 & -0.00508 & 0.0246^{*} & 0.0173 & 0.00939 & -0.00564 \\ & (0.0120) & (0.0129) & (0.0273) & (0.0127) & (0.0134) & (0.0160) & (0.00805) \\ \text { EDU } & 0.111 & 0.600 & 0.108 & 0.201 & 0.0133 & 0.700 & 1.251^{* * *} \\ & (0.623) & (0.679) & (1.555) & (0.628) & (0.705) & (0.871) & (0.331) \\ \text { URBAN } & -0.476 & -0.137 & -0.272 & -0.516 & -0.459 & -0.00521 & -0.375 \\ & (0.368) & (0.380) & (0.831) & (0.374) & (0.400) & (0.436) & (0.263) \\ \text { DENSITY } & 0.300 & 0.581 & 1.424^{*} & -0.0562 & 0.320 & 0.798^{*} & 0.212 \\ & (0.224) & (0.366) & (0.719) & (0.367) & (0.222) & (0.431) & (0.209) \\ \text { OVER65 } & 3.247^{*} & -3.397 & 2.682 & 2.652 & 3.062 & -7.353^{* *} & -2.459^{*} \\ & (1.841) & (2.522) & (5.715) & (1.845) & (2.034) & (3.473) & (1.249) \\ \text { UNDER25 } & 4.821^{* * *} & 3.318^{*} & 0.305 & 6.727^{* * *} & 4.797^{* * *} & 1.445 & 0.0176 \\ & (1.456) & (1.661) & (4.426) & (1.696) & (1.591) & (2.298) & (1.055) \\ \text { HOMEOWN } & -0.862 & -1.352 & 0.314 & -0.694 & -0.979 & -1.344 & -0.782^{*} \\ & (0.781) & (1.178) & (2.006) & (1.194) & (0.735) & (1.208) & (0.417) \\ \text { LIB } & 0.0158 & 0.0329 & -0.131 & 0.00323 & 0.0243 & 0.0510 & 0.0614^{* * *} \\ & (0.0363) & (0.0380) & (0.0997) & (0.0370) & (0.0401) & (0.0466) & (0.0161) \\ \text { SIZE } & -1.997 & -1.911 & -1.631 & -1.771 & -2.560 & -1.341 & -0.469 \\ & (1.850) & (2.086) & (5.175) & (1.768) & (1.981) & (2.477) & (1.620) \\ \text { Year Dummies } & \text { Yes } & \text { Yes } & \text { Yes } & \text { Yes } & \text { Yes } & \text { Yes } & \text { Yes } \\ \text { Observations } & 1,344 & 1,344 & 1,342 & 1,344 & 1,344 & 1,344 & 1,344 \\ \text { R-squared } & 0.540 & 0.460 & 0.126 & 0.446 & 0.516 & 0.428 & 0.760\end{array}$

Table 9: Robustness to excluding Alaska and Hawaii. Regression of spending on population growth and the fraction of stayers and their lags, including controls. Year dummies are included, and standard errors are clustered at the state level. Significance is indicated at the $1 \%(* * *), 5 \%$ $(* *)$, and $10 \%(*)$ levels. 


\begin{tabular}{|c|c|c|c|c|c|c|}
\hline VARIABLES & $\begin{array}{c}(1) \\
\text { TOTCAP }\end{array}$ & $\begin{array}{c}(2) \\
\text { NHCAP }\end{array}$ & $\begin{array}{c}(3) \\
\text { EQUIP\& LAND }\end{array}$ & $\begin{array}{c}(4) \\
\text { CONSTR }\end{array}$ & $\begin{array}{c}(5) \\
\text { NHCONSTR }\end{array}$ & $\begin{array}{c}(6) \\
\text { CURRENT }\end{array}$ \\
\hline $\mathrm{POPGR}_{t}$ & $\begin{array}{c}-0.00532 \\
(1.628)\end{array}$ & $\begin{array}{l}-0.342 \\
(2.093)\end{array}$ & $\begin{array}{c}2.171 \\
(1.910)\end{array}$ & $\begin{array}{l}-0.566 \\
(1.737)\end{array}$ & $\begin{array}{l}-0.981 \\
(2.329)\end{array}$ & $\begin{array}{l}-1.723 \\
(1.065)\end{array}$ \\
\hline $\mathrm{POPGR}_{t-1}$ & $\begin{array}{l}3.702^{* * *} \\
(1.132)\end{array}$ & $\begin{array}{l}3.729^{* * *} \\
(1.192)\end{array}$ & $\begin{array}{l}3.327^{* *} \\
(1.521)\end{array}$ & $\begin{array}{l}3.795^{* *} \\
(1.435)\end{array}$ & $\begin{array}{l}3.986^{* *} \\
(1.667)\end{array}$ & $\begin{array}{l}-0.198 \\
(0.508)\end{array}$ \\
\hline POPGR $_{t-2}$ & $\begin{array}{l}-1.679 \\
(1.307)\end{array}$ & $\begin{array}{l}-0.105 \\
(1.632)\end{array}$ & $\begin{array}{l}1.862 \\
(1.944)\end{array}$ & $\begin{array}{l}-2.494^{*} \\
(1.403)\end{array}$ & $\begin{array}{l}-0.857 \\
(1.838)\end{array}$ & $\begin{array}{l}-0.454 \\
(0.419)\end{array}$ \\
\hline $\mathrm{POPGR}_{t-3}$ & $\begin{array}{l}3.529^{* *} \\
(1.403)\end{array}$ & $\begin{array}{l}3.584^{* *} \\
(1.643)\end{array}$ & $\begin{array}{l}3.170^{*} \\
(1.736)\end{array}$ & $\begin{array}{l}3.570^{* *} \\
(1.641)\end{array}$ & $\begin{array}{l}4.004^{*} \\
(2.022)\end{array}$ & $\begin{array}{c}-0.0781 \\
(0.537)\end{array}$ \\
\hline $\mathrm{POPGR}_{t-4}$ & $\begin{array}{l}-1.570 \\
(2.707)\end{array}$ & $\begin{array}{c}0.178 \\
(2.675)\end{array}$ & $\begin{array}{c}-6.187^{* *} \\
(2.925)\end{array}$ & $\begin{array}{l}-0.536 \\
(2.963)\end{array}$ & $\begin{array}{l}2.746 \\
(3.018)\end{array}$ & $\begin{array}{l}-0.656 \\
(1.010)\end{array}$ \\
\hline $\mathrm{STAY}_{t}$ & $\begin{array}{c}-6.901^{* *} \\
(2.644)\end{array}$ & $\begin{array}{l}-1.282 \\
(3.515)\end{array}$ & $\begin{array}{c}-8.726^{*} \\
(4.755)\end{array}$ & $\begin{array}{c}-6.850^{* *} \\
(2.703)\end{array}$ & $\begin{array}{c}0.861 \\
(4.817)\end{array}$ & $\begin{array}{c}0.851 \\
(1.947)\end{array}$ \\
\hline $\operatorname{STAY}_{t-1}$ & $\begin{array}{l}-4.090 \\
(2.476)\end{array}$ & $\begin{array}{l}-2.935 \\
(2.722)\end{array}$ & $\begin{array}{l}-0.773 \\
(4.787)\end{array}$ & $\begin{array}{l}-4.995^{* *} \\
(2.477)\end{array}$ & $\begin{array}{l}-4.034 \\
(2.907)\end{array}$ & $\begin{array}{l}-2.382^{*} \\
(1.303)\end{array}$ \\
\hline $\mathrm{STAY}_{t-2}$ & $\begin{array}{c}8.247^{* * *} \\
(2.997)\end{array}$ & $\begin{array}{l}9.247^{* *} \\
(3.815)\end{array}$ & $\begin{array}{c}2.549 \\
(4.205)\end{array}$ & $\begin{array}{c}9.660^{* * *} \\
(3.146)\end{array}$ & $\begin{array}{l}11.70^{* * *} \\
(4.358)\end{array}$ & $\begin{array}{c}4.786^{* * *} \\
(1.469)\end{array}$ \\
\hline $\mathrm{STAY}_{t-3}$ & $\begin{array}{l}-1.170 \\
(2.833)\end{array}$ & $\begin{array}{l}-3.383 \\
(3.234)\end{array}$ & $\begin{array}{l}-9.165^{*} \\
(4.781)\end{array}$ & $\begin{array}{c}0.877 \\
(3.129)\end{array}$ & $\begin{array}{l}-1.578 \\
(3.683)\end{array}$ & $\begin{array}{c}-2.392^{* * *} \\
(0.791)\end{array}$ \\
\hline STAY $_{t-4}$ & $\begin{array}{c}-7.697^{* *} \\
(3.364)\end{array}$ & $\begin{array}{c}-9.207^{* *} \\
(4.471)\end{array}$ & $\begin{array}{l}9.888^{* *} \\
(4.416)\end{array}$ & $\begin{array}{c}-11.88^{* * *} \\
(3.733)\end{array}$ & $\begin{array}{c}-14.92^{* * *} \\
(5.232)\end{array}$ & $\begin{array}{c}-5.318^{* *} \\
(2.528)\end{array}$ \\
\hline $\begin{array}{l}\text { Sums of coefficients: } \\
\text { POPGR, undiscounted: }\end{array}$ & $\begin{array}{l}3.98 \\
(2.78)\end{array}$ & $\begin{array}{l}7.04^{* *} \\
(3.24)\end{array}$ & $\begin{array}{c}4.34 \\
(3.06)\end{array}$ & $\begin{array}{c}3.77 \\
(3.03)\end{array}$ & $\begin{array}{l}8.90^{* *} \\
(3.67)\end{array}$ & $\begin{array}{c}-3.11^{* *} \\
(1.50)\end{array}$ \\
\hline POPGR, discounted $\left(B_{n}\right)$ : & $\begin{array}{c}4.62 \\
(4.16)\end{array}$ & $\begin{array}{l}9.43^{*} \\
(4.89)\end{array}$ & $\begin{array}{c}2.59 \\
(4.67)\end{array}$ & $\begin{array}{c}4.92 \\
(4.52)\end{array}$ & $\begin{array}{l}13.1^{* *} \\
(5.71)\end{array}$ & $\begin{array}{l}-3.77^{*} \\
(2.14)\end{array}$ \\
\hline STAY, undiscounted $\left(B_{\theta}^{*}\right)$ : & $\begin{array}{l}-11.6^{* * *} \\
(3.68)\end{array}$ & $\begin{array}{c}-7.56^{* *} \\
(3.83)\end{array}$ & $\begin{array}{l}-6.23 \\
(4.33)\end{array}$ & $\begin{array}{c}-13.2^{* * *} \\
(3.71)\end{array}$ & $\begin{array}{c}-7.97^{* *} \\
(4.04)\end{array}$ & $\begin{array}{c}-4.46^{*} \\
(2.28)\end{array}$ \\
\hline STAY, discounted $\left(B_{\theta}\right)$ : & $\begin{array}{l}-12.6^{* * *} \\
(3.95)\end{array}$ & $\begin{array}{l}-9.00^{* *} \\
(4.19)\end{array}$ & $\begin{array}{l}-5.47 \\
(4.56)\end{array}$ & $\begin{array}{l}-14.6^{* * *} \\
(3.97)\end{array}$ & $\begin{array}{l}-10.0^{* *} \\
(4.42)\end{array}$ & $\begin{array}{l}-5.42^{* *} \\
(2.65)\end{array}$ \\
\hline
\end{tabular}

Table 10: Continued on the next page 


$\begin{array}{lcccccc} & (1) & (2) & (3) & (4) & (5) & (6) \\ \text { VARIABLES } & \text { TOTCAP } & \text { NHCAP } & \text { EQUIP\& LAND } & \text { CONSTR } & \text { NHCONSTR } & \text { CURRENT } \\ \text { INTMIG } & 0.0411 & -0.461 & 0.611 & -0.176 & -0.856 & -0.601 \\ & (1.017) & (0.994) & (1.189) & (1.082) & (1.059) & (0.696) \\ \text { STATEINC } & 0.0409^{* * *} & 0.0416^{* * *} & 0.0217^{*} & 0.0458^{* * *} & 0.0506^{* * *} & 0.0203^{* *} \\ & (0.0114) & (0.0125) & (0.0116) & (0.0118) & (0.0136) & (0.00777) \\ \text { EDU } & 0.266 & 0.299 & 0.809 & 0.0983 & 0.0574 & 0.904^{* * *} \\ & (0.540) & (0.595) & (0.540) & (0.571) & (0.654) & (0.273) \\ \text { URBAN } & 0.162 & 0.568^{*} & 0.200 & 0.186 & 0.740^{* *} & -0.376^{*} \\ & (0.303) & (0.311) & (0.263) & (0.324) & (0.324) & (0.215) \\ \text { DENSITY } & -0.499^{* *} & -0.661^{* * *} & -0.501^{*} & -0.503^{* *} & -0.720^{* * *} & 0.0418 \\ & (0.206) & (0.212) & (0.252) & (0.216) & (0.230) & (0.152) \\ \text { OVER65 } & 2.105 & -0.660 & 0.683 & 2.450 & -0.955 & -1.761 \\ & (1.614) & (1.888) & (1.872) & (1.696) & (2.143) & (1.247) \\ \text { UNDER25 } & 4.368^{* * *} & 3.004^{* *} & 3.231^{* *} & 4.571^{* * *} & 2.811^{*} & 0.698 \\ & (1.279) & (1.433) & (1.380) & (1.327) & (1.568) & (0.968) \\ \text { HOMEOWN } & -0.369 & -0.489 & 0.336 & -0.555 & -0.758 & -0.650 \\ & (0.632) & (0.626) & (0.744) & (0.650) & (0.666) & (0.438) \\ \text { LIB } & 0.0123 & 0.00717 & -0.00215 & 0.0151 & 0.000610 & 0.00739 \\ & (0.0374) & (0.0361) & (0.0345) & (0.0402) & (0.0418) & (0.0198) \\ \text { SIZE } & 1.006 & 2.036 & 1.811 & 0.691 & 2.050 & 1.961^{*} \\ & (1.819) & (2.063) & (2.111) & (1.928) & (2.317) & (1.012) \\ \text { Year Dummies } & \text { Yes } & \text { Yes } & \text { Yes } & \text { Yes } & \text { Yes } & \text { Yes } \\ & & & & & & 1,300 \\ \text { Observations } & 1,300 & 1,300 & 1,300 & 1,300 & 1,300 \\ \text { R-squared } & 0.692 & 0.696 & 0.601 & 0.666 & 0.669 & 0.624\end{array}$

Table 10: Robustness to including local spending: Regression of the sum of state and local spending on population growth and the fraction of stayers and their lags (at the state level), including controls. Year dummies are included, and standard errors are clustered at the state level. Significance is indicated at the $1 \%(* * *), 5 \%(* *)$, and $10 \%(*)$ levels. 


VARIABLES $_{\text {POPGR }_{t}}$
POPGR $_{t-1}$
POPGR $_{t-2}$
POPGR $_{t-3}$
POPGR $_{t-4}$
STAY $_{t}$
STAY $_{t-1}$
STAY $_{t-2}$
STAY $_{t-3}$
STAY $_{t-4}$

Sums of coefficients:

POPGR, undiscounted:

POPGR, discounted $\left(B_{n}\right)$ :

STAY, undiscounted $\left(B_{\theta}^{*}\right)$ :

STAY, discounted $\left(B_{\theta}\right)$ :
(1) TOTCAP NHCAP LAND

(4)

(5)

EQUIP

CONSTR

$\begin{array}{ccccccc}4.714 & 10.31 & 14.79 & 5.487 & 3.338 & 8.252 & 9.488^{* * *} \\ (4.753) & (6.614) & (19.31) & (4.242) & (5.268) & (8.946) & (2.409) \\ 7.144^{* *} & 9.054^{* *} & 12.99 & 6.439 & 6.730^{* *} & 10.00^{*} & 3.158^{* *} \\ (2.796) & (3.886) & (8.316) & (4.706) & (3.129) & (5.181) & (1.365) \\ -0.594 & -1.965 & 9.213 & -2.542 & -0.876 & -2.224 & 1.311 \\ (2.919) & (4.018) & (9.036) & (3.091) & (3.297) & (5.334) & (0.913) \\ 1.700 & -0.0200 & 2.013 & 3.973 & 1.416 & -0.172 & -2.419^{*} \\ (1.923) & (4.377) & (9.013) & (2.720) & (2.262) & (5.745) & (1.269) \\ -12.60^{* * *} & -14.13^{* *} & -5.171 & -7.674^{*} & -13.94^{* * *} & -17.53^{* *} & -6.617^{* * *} \\ (4.487) & (5.912) & (12.66) & (4.186) & (5.147) & (7.051) & (2.359) \\ -13.65^{* *} & -0.734 & -6.146 & -5.942 & -14.49^{* *} & -0.0914 & 2.097 \\ (5.663) & (6.356) & (23.89) & (7.473) & (6.125) & (7.343) & (3.865) \\ -10.07^{* *} & -8.123 & -9.976 & -7.665 & -11.96^{* *} & -10.27 & 1.030 \\ (4.714) & (6.187) & (16.04) & (5.727) & (5.119) & (7.201) & (3.040) \\ 5.675 & -4.575 & 30.85^{*} & 4.595 & 4.906 & -9.533 & 2.975 \\ (6.921) & (9.508) & (17.23) & (6.416) & (7.619) & (11.91) & (2.481) \\ -0.871 & -3.976 & -12.82 & -6.681 & -0.169 & 0.735 & -1.788 \\ (8.617) & (10.78) & (18.02) & (7.542) & (9.309) & (14.05) & (2.362) \\ -3.350 & 2.169 & -1.394 & 0.925 & -2.375 & 1.997 & -13.91^{* * *} \\ (6.293) & (12.77) & (19.85) & (7.712) & (6.650) & (16.78) & (4.732) \\ & & & & & & \\ 0.361 & 3.25 & 33.8 & 5.68 & -3.33 & -1.67 & 4.92 \\ (9.19) & (12.6) & (31.5) & (6.77) & (10.5) & (16.4) & (5.53) \\ -6.82 & -6.00 & 35.8 & 2.38 & -11.7 & -13.3 & -0.0673 \\ (12.0) & (17.1) & (41.5) & (8.52) & (13.7) & (21.7) & (7.75) \\ -22.3^{* * *} & -15.2^{* * *} & 0.509 & -14.8^{* * *} & -24.1^{* * *} & -17.2^{* * *} & -9.60^{* * *} \\ (3.56) & (4.35) & (12.2) & (3.10) & (3.92) & (5.38) & (3.10) \\ -22.9^{* * *} & -16.1^{* * *} & 0.804 & -15.4^{* * *} & -24.6^{* * *} & -18.0^{* * *} & -12.1^{* * *} \\ (3.99) & (5.28) & (12.6) & (3.13) & (4.31) & (6.27) & (3.90) \\ & & & & & & \end{array}$

Table 11: Continued on the next page

(7)

CONSTR CURRENT 
VARIABLES

INTMIG

STATEINC

EDU

URBAN

DENSITY

OVER65

UNDER25

$\stackrel{8}{8}$

\section{HOMEOWN}

LIB

SIZE
(1)

\section{TOTCA}

(2)

(3)

$-1.903$ NHCAP

LAND

(4)

$-4.243^{* *}$

$-1.315$

(2.932)

(1.638)

$0.0257^{* *}$

$(1.697)$

0.0173

$0.0308^{* *}$

(0.0124)

$(0.0150)$

$(0.0276)$

$(0.0123)$

$-0.038$

0.350

$-0.433$

0.0426

$(0.692)$

(0.706)

(0.802)

(1.568)

$-0.603$

$-0.320$

(0.328)

(0.405)

(0.827)

$-0.192$

0.212

0.227

0.766

(0.271)

(0.647)

1.584

$-4.870$

$-1.410$

(1.940)

(1.941)

(2.928)

(7.112)

$-0.31$

$6.300^{* *}$

(2.338)

(1.585)

$-1.074$

$-2.199^{* *}$

(5.743)

(1.813)

$-1.032$

$-0.954$

(0.946)

0.0222

$(0.948)$

(2.034)

(0.0378)

$-1.778$

0.0671

(0.0446)

$-0.0878$

$-1.626$

(2.374)

$-2.132$

(5.953)

0.00917

(0.0391)

$-1.860$

(1.887)

Table 11: Continued on the next page
(5)

CONSTR

$$
\begin{gathered}
-1.484 \\
(1.227) \\
0.0259^{*} \\
(0.0134) \\
-0.105 \\
(0.789) \\
-0.593 \\
(0.365) \\
0.266 \\
(0.174) \\
2.319 \\
(2.007) \\
5.308^{* * *} \\
(1.645) \\
-1.135 \\
(0.754) \\
0.0292 \\
(0.0410) \\
-2.270 \\
(1.905)
\end{gathered}
$$

(6)

NHCONSTR

$-4.711^{*}$

(1.843)

0.0278

$(0.0175)$

0.506

$(1.023)$

0.0370

$(0.495)$

0.372

$(0.401)$

$-8.873^{* *}$

(3.804)

2.982

(2.876)

$-2.433^{* *}$

(1.048)

$0.0946^{*}$

(0.0508)

$-0.820$

(2.675)
(7)

CURRENT

$-3.004^{* * *}$

$(0.771)$

0.00822

(0.00989)

$0.925^{* *}$

$(0.363)$

$-0.764^{* *}$

(0.294)

0.198

(0.222)

$-4.008^{* *}$

(1.865)

0.164

(1.379)

$-1.001^{*}$

(0.511)

$0.0673^{* * *}$

(0.0200)

$-0.184$

(1.589) 


\begin{tabular}{|c|c|c|c|c|c|c|c|}
\hline VARIABLES & $\begin{array}{c}(1) \\
\text { TOTCAP }\end{array}$ & $\begin{array}{c}(2) \\
\text { NHCAP }\end{array}$ & $\begin{array}{c}(3) \\
\text { LAND }\end{array}$ & $\begin{array}{c}(4) \\
\text { EQUIP }\end{array}$ & $\begin{array}{c}(5) \\
\text { CONSTR }\end{array}$ & $\begin{array}{c}(6) \\
\text { NHCONSTR }\end{array}$ & $\begin{array}{c}(7) \\
\text { CURRENT }\end{array}$ \\
\hline $\mathrm{NETMIG}_{t}$ & $\begin{array}{l}-6.128 \\
(6.567)\end{array}$ & $\begin{array}{l}-13.59 \\
(10.34)\end{array}$ & $\begin{array}{l}-9.778 \\
(25.90)\end{array}$ & $\begin{array}{l}-6.266 \\
(6.950)\end{array}$ & $\begin{array}{l}-6.239 \\
(6.944)\end{array}$ & $\begin{array}{l}-13.81 \\
(12.47)\end{array}$ & $\begin{array}{c}-14.78^{* * *} \\
(2.765)\end{array}$ \\
\hline NETMIG $_{t-1}$ & $\begin{array}{l}-0.271 \\
(4.026)\end{array}$ & $\begin{array}{l}-1.313 \\
(5.611)\end{array}$ & $\begin{array}{l}-8.973 \\
(8.947)\end{array}$ & $\begin{array}{c}4.390 \\
(4.002)\end{array}$ & $\begin{array}{c}0.454 \\
(4.470)\end{array}$ & $\begin{array}{l}-1.700 \\
(7.134)\end{array}$ & $\begin{array}{c}-3.584^{*} \\
(2.056)\end{array}$ \\
\hline NETMIG $_{t-2}$ & $\begin{array}{l}-3.979 \\
(5.642)\end{array}$ & $\begin{array}{c}6.103 \\
(7.373)\end{array}$ & $\begin{array}{l}-16.07 \\
(12.66)\end{array}$ & $\begin{array}{l}-0.884 \\
(4.626)\end{array}$ & $\begin{array}{l}-4.136 \\
(6.131)\end{array}$ & $\begin{array}{c}8.636 \\
(9.162)\end{array}$ & $\begin{array}{l}-0.855 \\
(1.157)\end{array}$ \\
\hline NETMIG $_{t-3}$ & $\begin{array}{l}2.377 \\
(5.303)\end{array}$ & $\begin{array}{c}2.597 \\
(7.068)\end{array}$ & $\begin{array}{l}-0.364 \\
(15.73)\end{array}$ & $\begin{array}{l}1.088 \\
(4.739)\end{array}$ & $\begin{array}{c}2.602 \\
(5.419)\end{array}$ & $\begin{array}{l}3.025 \\
(8.531)\end{array}$ & $\begin{array}{c}0.954 \\
(2.243)\end{array}$ \\
\hline NETMIG $_{t-4}$ & $\begin{array}{c}6.467 \\
(4.156)\end{array}$ & $\begin{array}{l}5.534 \\
(7.455)\end{array}$ & $\begin{array}{l}19.54 \\
(14.19)\end{array}$ & $\begin{array}{l}-4.928 \\
(6.661)\end{array}$ & $\begin{array}{l}7.352 \\
(4.543)\end{array}$ & $\begin{array}{l}9.664 \\
(10.19)\end{array}$ & $\begin{array}{r}8.793^{* * *} \\
(2.523)\end{array}$ \\
\hline $\begin{array}{l}\text { Year Dummies } \\
\text { Sum of coefficients on net migration: }\end{array}$ & Yes & Yes & Yes & Yes & Yes & Yes & Yes \\
\hline NETMIG, undiscounted: & $\begin{array}{l}-1.53 \\
(11.2)\end{array}$ & $\begin{array}{c}-0.674 \\
(15.8)\end{array}$ & $\begin{array}{l}-15.7 \\
(36.0)\end{array}$ & $\begin{array}{l}-6.60 \\
(9.66)\end{array}$ & $\begin{array}{c}0.0326 \\
(12.1)\end{array}$ & $\begin{array}{c}5.82 \\
(19.9)\end{array}$ & $\begin{array}{c}-9.47^{*} \\
(5.64)\end{array}$ \\
\hline Observations & 1,400 & 1,400 & 1,398 & 1,400 & 1,400 & 1,400 & 1,400 \\
\hline R-squared & 0.637 & 0.577 & 0.109 & 0.540 & 0.611 & 0.534 & 0.760 \\
\hline
\end{tabular}

Table 11: Robustness to controlling for net migration: Regression of spending on population growth, the fraction of stayers, net migration, and their lags, including controls. Year dummies are included, and standard errors are clustered at the state level. Significance is indicated at the $1 \%$ $(* * *), 5 \%(* *)$, and $10 \%(*)$ levels. 


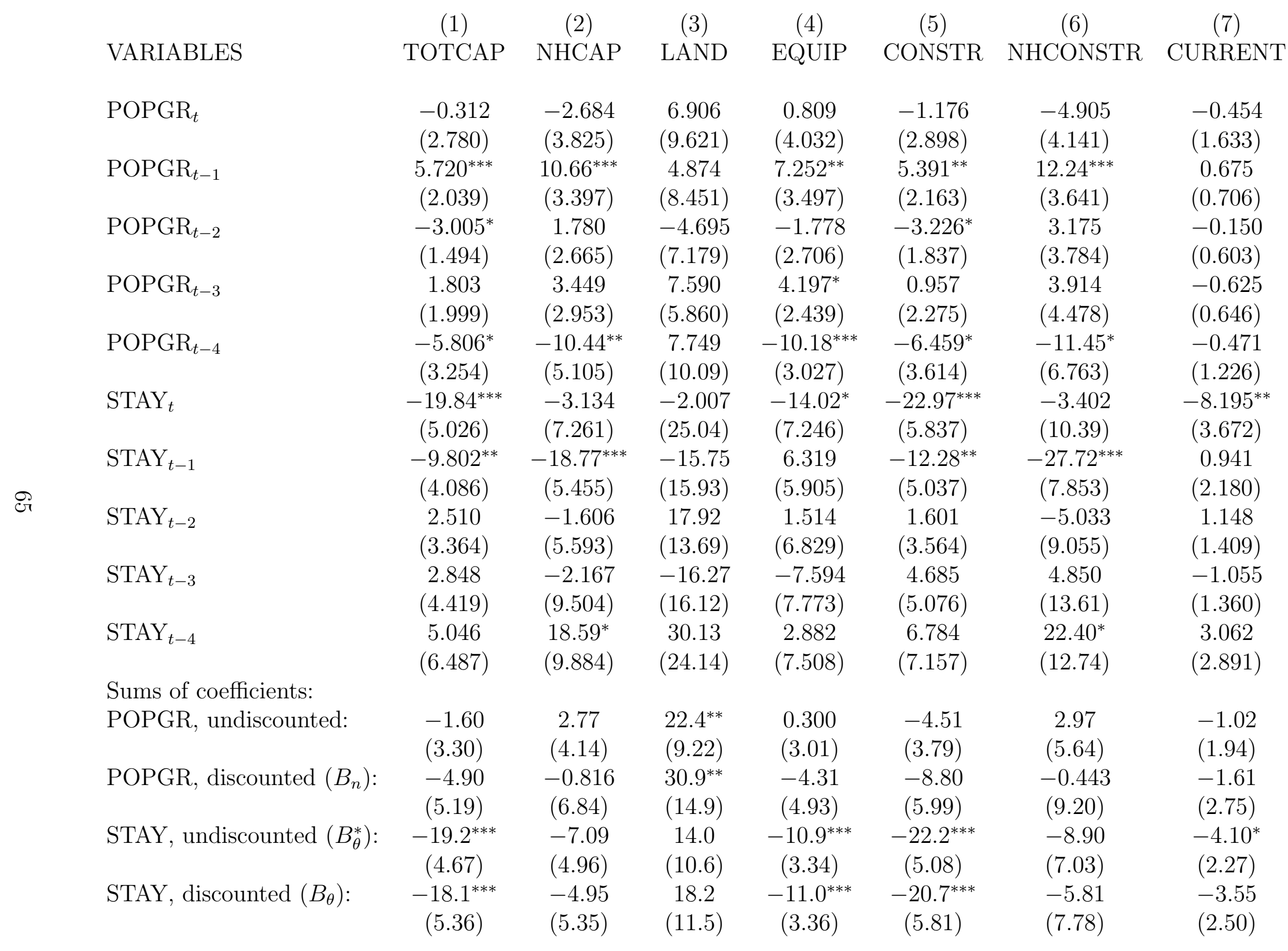

Table 12: Continued on the next page 


$\begin{array}{lccccccc} & (1) & (2) & (3) & (4) & (5) & (6) & (7) \\ \text { VARIABLES } & \text { TOTCAP } & \text { NHCAP } & \text { LAND } & \text { EQUIP } & \text { CONSTR } & \text { NHCONSTR } & \text { CURRENT } \\ & & & & & & & \\ \text { INTMIG } & -1.121 & -2.260 & 2.676 & -2.076 & -0.767 & -2.243 & -2.952^{* * *} \\ & (1.508) & (2.110) & (3.361) & (2.052) & (1.456) & (2.181) & (0.757) \\ \text { STATEINC } & 0.0219 & 0.0135 & 0.0132 & 0.0259^{*} & 0.0244 & 0.0125 & -0.00521 \\ & (0.0136) & (0.0142) & (0.0273) & (0.0133) & (0.0151) & (0.0172) & (0.00903) \\ \text { EDU } & -0.151 & 0.449 & -0.261 & -0.00969 & -0.312 & 0.486 & 1.267^{* * *} \\ & (0.637) & (0.698) & (1.560) & (0.647) & (0.720) & (0.872) & (0.354) \\ \text { URBAN } & -0.421 & -0.0590 & -0.338 & -0.548 & -0.394 & 0.114 & -0.366 \\ & (0.364) & (0.387) & (0.865) & (0.372) & (0.394) & (0.448) & (0.266) \\ \text { DENSITY } & 0.312 & 0.619 & 1.403^{*} & -0.0108 & 0.334 & 0.852^{*} & 0.197 \\ & (0.239) & (0.382) & (0.734) & (0.347) & (0.236) & (0.463) & (0.216) \\ \text { OVER65 } & 3.058 & -3.388 & 3.704 & 2.549 & 2.905 & -7.429^{* *} & -2.610^{*} \\ & (1.912) & (2.677) & (5.885) & (1.721) & (2.092) & (3.669) & (1.297) \\ \text { UNDER25 } & 5.035^{* * *} & 3.478^{*} & 0.670 & 7.086^{* * *} & 5.135^{* * *} & 1.711 & -0.0800 \\ & (1.507) & (1.762) & (4.922) & (1.689) & (1.648) & (2.431) & (1.103) \\ \text { HOMEOWN } & -0.835 & -1.317 & 0.293 & -0.802 & -0.912 & -1.131 & -0.801^{*} \\ & (0.806) & (1.221) & (2.008) & (1.150) & (0.763) & (1.298) & (0.431) \\ \text { LIB } & 0.0139 & 0.0257 & -0.191^{*} & -0.00493 & 0.0257 & 0.0525 & 0.0614^{* * *} \\ & (0.0389) & (0.0408) & (0.102) & (0.0366) & (0.0428) & (0.0515) & (0.0168) \\ \text { SIZE } & -2.759 & -2.229 & -3.788 & -2.162 & -3.337 & -1.336 & -0.547 \\ & (1.950) & (2.232) & (5.387) & (1.723) & (2.100) & (2.678) & (1.685) \\ \text { POLCOMP } & -0.0186 & -0.206 & -0.0451 & 0.588^{*} & -0.0446 & -0.474 & -0.148 \\ \text { Year Dummies } & (0.233) & (0.318) & (0.933) & (0.295) & (0.256) & (0.406) & (0.167) \\ & \text { Yes } & \text { Yes } & \text { Yes } & \text { Yes } & \text { Yes } & \text { Yes } & \text { Yes } \\ \text { Observations } & & & & & & & 1,200 \\ \text { R-squared } & 1,200 & 1,200 & 1,198 & 1,200 & 1,200 & 1,200 & 1,200 \\ & 0.539 & 0.446 & 0.136 & 0.481 & 0.513 & 0.401 & 0.755\end{array}$

Table 12: Robustness to controlling for political competition: Regression of spending on population growth and the fraction of stayers and their lags, including controls. The measure of political competition from Besley, Persson, and Sturm [11] is included among the controls. Year dummies are included, and standard errors are clustered at the state level. Significance is indicated at the $1 \%(* *), 5 \%(* *)$, and $10 \%(*)$ levels. 


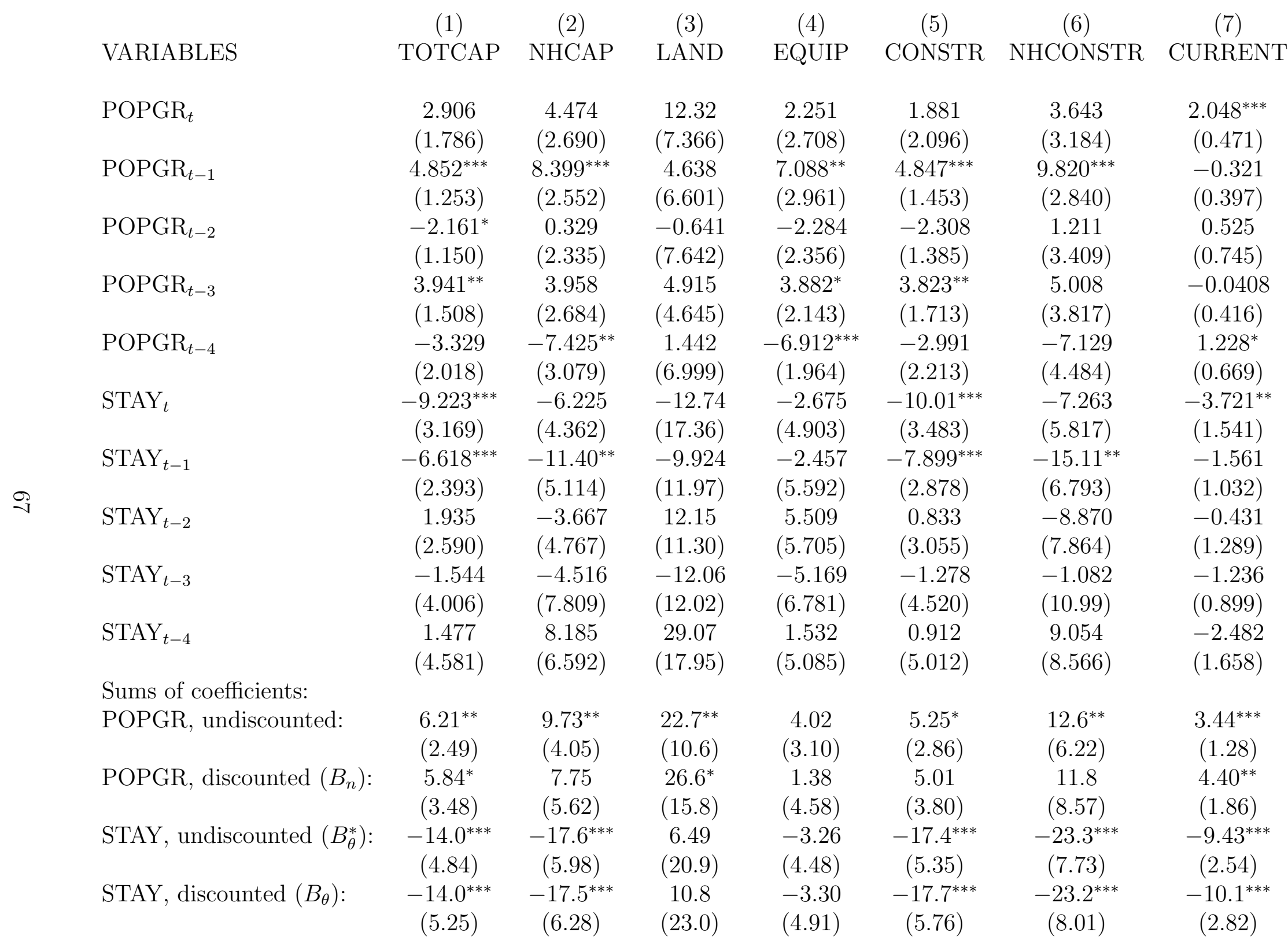

Table 13: Continued on the next page 


\begin{tabular}{|c|c|c|c|c|c|c|c|}
\hline \multirow{2}{*}{ VARIABLES } & (1) & $(2)$ & $(3)$ & (4) & $(5)$ & $(6)$ & $(7)$ \\
\hline & TOTCAP & NHCAP & LAND & EQUIP & CONSTR & NHCONSTR & CURRENT \\
\hline \multirow[t]{2}{*}{ INTMIG } & 2.885 & -0.854 & 3.064 & 0.807 & $3.261^{*}$ & 0.456 & 0.709 \\
\hline & $(1.759)$ & $(2.236)$ & $(6.354)$ & $(1.972)$ & $(1.890)$ & $(3.040)$ & $(0.743)$ \\
\hline \multirow[t]{2}{*}{ STATEINC } & $0.0350^{* * *}$ & $0.0569^{* * *}$ & -0.00836 & $0.0265^{* *}$ & $0.0361^{* * *}$ & $0.0661^{* * *}$ & 0.00159 \\
\hline & $(0.0115)$ & $(0.0133)$ & $(0.0603)$ & $(0.0112)$ & $(0.0131)$ & $(0.0178)$ & $(0.00557)$ \\
\hline \multirow[t]{2}{*}{ EDU } & -0.233 & 0.176 & $5.852^{*}$ & -0.956 & -0.645 & -0.455 & 0.217 \\
\hline & $(0.824)$ & $(0.868)$ & $(3.172)$ & $(0.795)$ & $(0.912)$ & $(1.294)$ & $(0.353)$ \\
\hline \multirow[t]{2}{*}{ URBAN } & -0.267 & 0.266 & 1.060 & -0.441 & -0.786 & 0.650 & 0.0370 \\
\hline & $(0.566)$ & $(0.811)$ & $(2.920)$ & $(0.616)$ & $(0.777)$ & $(1.236)$ & $(0.236)$ \\
\hline \multirow{2}{*}{ DENSITY } & -1.232 & $-3.673^{* *}$ & $10.28^{* *}$ & 1.851 & -2.013 & $-7.320^{* * *}$ & -0.812 \\
\hline & $(1.358)$ & $(1.730)$ & $(4.916)$ & $(1.431)$ & $(1.488)$ & $(2.546)$ & $(0.701)$ \\
\hline \multirow[t]{2}{*}{ OVER65 } & 1.702 & 1.177 & -10.15 & 2.251 & 0.871 & -1.569 & 0.000207 \\
\hline & $(3.222)$ & $(4.106)$ & (13.38) & $(2.911)$ & $(3.856)$ & $(4.873)$ & $(1.369)$ \\
\hline \multirow[t]{2}{*}{ UNDER25 } & 0.461 & 0.834 & 1.230 & 2.147 & -1.193 & -1.185 & -0.337 \\
\hline & $(2.221)$ & $(2.825)$ & $(8.522)$ & $(2.228)$ & $(2.756)$ & $(4.067)$ & $(1.060)$ \\
\hline \multirow[t]{2}{*}{ HOMEOWN } & -0.315 & -0.646 & -0.108 & -0.122 & -0.341 & -0.520 & -0.286 \\
\hline & $(0.602)$ & $(0.753)$ & $(2.076)$ & $(0.667)$ & $(0.696)$ & $(1.061)$ & $(0.228)$ \\
\hline \multirow[t]{2}{*}{ LIB } & $-0.0447^{*}$ & $-0.0600^{*}$ & -0.123 & 0.00876 & -0.0388 & -0.0695 & -0.0150 \\
\hline & $(0.0224)$ & $(0.0320)$ & $(0.114)$ & $(0.0275)$ & $(0.0272)$ & $(0.0436)$ & $(0.00931)$ \\
\hline \multirow[t]{2}{*}{ SIZE } & 1.127 & 8.005 & 25.63 & $-22.99^{*}$ & 1.883 & 13.04 & $6.960^{*}$ \\
\hline & $(7.868)$ & $(8.013)$ & $(33.64)$ & $(11.50)$ & $(8.074)$ & $(10.55)$ & $(4.034)$ \\
\hline Year Dummies & Yes & Yes & Yes & Yes & Yes & Yes & Yes \\
\hline State Dummies & Yes & Yes & Yes & Yes & Yes & Yes & Yes \\
\hline Observations & 1,400 & 1,400 & 1,398 & 1,400 & 1,400 & 1,400 & 1,400 \\
\hline R-squared & 0.839 & 0.800 & 0.417 & 0.741 & 0.814 & 0.747 & 0.963 \\
\hline
\end{tabular}

Table 13: Robustness to including state fixed effects: Regression of spending on population growth and the fraction of stayers and their lags, including controls. State and year dummies are included. Significance is indicated at the $1 \%(* * *), 5 \%(* *)$, and $10 \%(*)$ levels. 